\title{
HEALTH AND SAFETY CONSIDERATIONS ASSOCIATED WITH SODIUM-COOLED EXPERIMENTAL NUCLEAR FUEL DISMANTLEMENT
}

\author{
Alan E. Carvo
}

April 2015

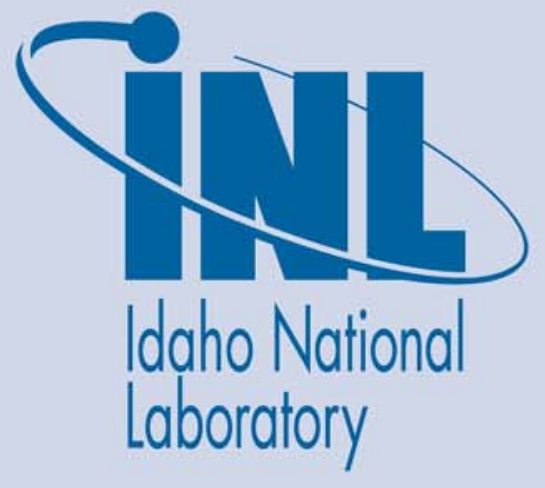

The INL is a U.S. Department of Energy National Laboratory operated by Battelle Energy Alliance 


\title{
HEALTH AND SAFETY CONSIDERATIONS ASSOCIATED WITH SODIUM-COOLED EXPERIMENTAL NUCLEAR FUEL DISMANTLEMENT
}

\author{
Alan E. Carvo
}

April 2015

\begin{abstract}
Idaho National Laboratory
Idaho Falls, Idaho 83415
\end{abstract}

http://www.inl.gov

Prepared for the

U.S. Department of Energy

Office of Nuclear Energy

Under DOE Idaho Operations Office

Contract DE-AC07-05ID14517 


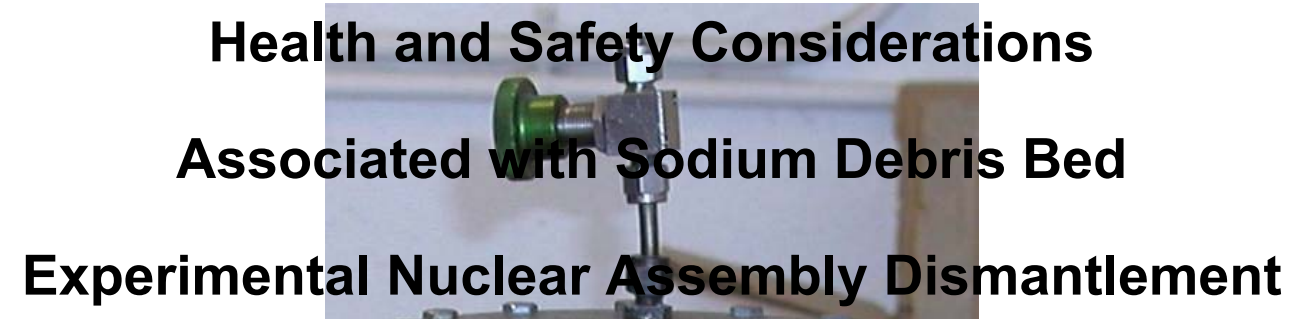

Experimental Nuclear Assembly Dismantlement

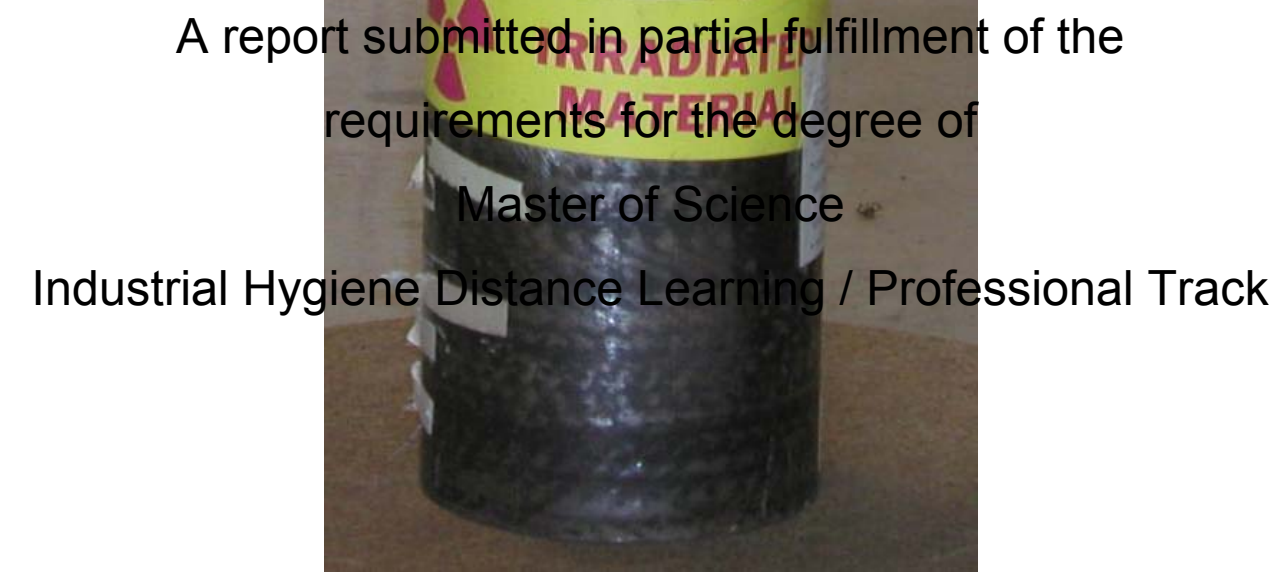

Montana Tech of the University of Montana

Spring 2015 


\section{Executive Summary}

As the end of World War II approached, scientists who developed the processes to generate nuclear material for war-time use grew interested in applying those technologies to the generation of power for cities across the United States. Concerns about the availability of natural uranium led to the development of self-fueling fast neutron breeder reactors. In order to produce plutonium at a rate greater than the consumption of uranium during a nuclear chain reaction, high-energy "fast" neutrons are required. Fast neutron reactors utilize low melting-point metals, like sodium, to provide cooling.

After the earliest reactors experienced trouble providing adequate cooling during upsets, resulting in partial melt-downs, experiments were designed to test fuel and cooling material arrangements that would improve cooling characteristics, even in the event of partial damage to reactor components. In a sodium-cooled reactor, damaged components from a high temperature excursion may involve nuclear fuel, liquid sodium coolant, thermal insulation, and other instrumentation. This combination of damaged material is referred to as a sodium debris bed.

Between the mid-1970s and the mid-1980s Sandia National Laboratory constructed eleven experimental assemblies to simulate debris beds formed in a sodium-cooled fast breeder reactor. All but one of the assemblies were irradiated. The experimental assemblies were transferred to the Idaho National Laboratory (INL) in 2007 and 2008 for storage, dismantlement, recovery of the uranium for reuse in the nuclear fuel cycle, and disposal of unneeded materials. The effort to recover this fuel is termed the INL Sodium Debris Bed Material Treatment Project.

The assemblies are comprised of nested layers of metal and thermal insulation innervated by a variety of monitoring instrumentation. In the center of the assembly is a primary containment vessel holding a crucible of enriched uranium oxide fuel surrounded by a blanket of metallic sodium. Due to the additional time required to design and install equipment necessary to separate the sodium from the uranium product, the project was broken into two phases. The first encompasses dismantlement and recovery of the primary containment vessel for temporary storage. The second phase involves separation of the sodium from the uranium product. This report deals with the dismantlement phase of this project.

After identification of all disciplines responsible for, or impacted by, elements of the effort, a series of trade studies were conducted to identify appropriate facilities; means of exposure control; transfer, disassembly, and repackaging strategies; and preferred assembly processing order. Concurrently, an effort was undertaken to identify and compile all applicable regulations, codes, standards, procedures, or other requirements. Physical and chemical hazards including radiation, material handling, asbestos, and sodium, and the controls implemented are discussed.

Prior to operations, full-scale mock-ups with realistic surrogate assemblies were completed, as well as internal and independent self-assessments to demonstrate the readiness of facilities, staff, and operating procedures. Dismantling operations commenced in late 2014 and are ongoing. Lessons learned from the effort to date are presented. The use of realistic mock-ups and attention to the order in which assemblies are processed are largely credited for project success to date.

\section{Keywords:}

Idaho National Laboratory, sodium, dismantlement, experimental assembly, debris bed 


\section{Dedication}

I would like to express sincere gratitude to my wife, Dana, and daughters, Emma and Grace, for their support and understanding during the past few years when weekends were primarily comprised of homework rather than other family activities. I could not have completed this coursework without your support. 


\section{Acknowledgements}

I would like to acknowledge the support of Idaho National Laboratory personnel including project management, operations, ES\&H, and radiological controls. These include Paul Fuhrman, Mark Osment, Evan Nef, Mark Borland, Kevin Croft, Steve Yarnell, Charlene Johnson, Lynne Coe-Leavitt, and Paul Nelson. These individuals provided background documentation and photographs and responded to numerous questions related to the dismantlement project. This report could not have been completed without their assistance. 


\section{Table of Contents}

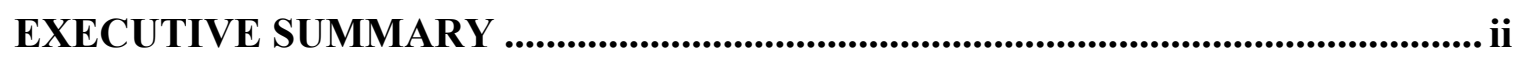

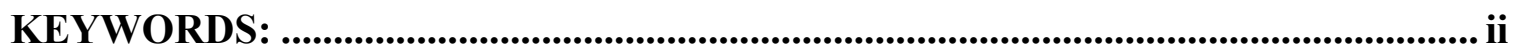

DEDICATION.........................................................................................................................ii

ACKNOWLEDGEMENTS ........................................................................................... iv

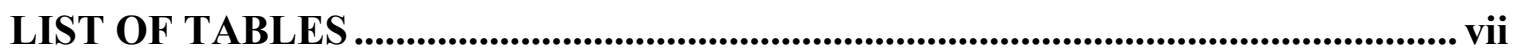

LIST OF FIGURES ............................................................................................................... viii

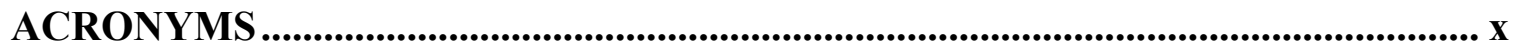

1. INTRODUCTION

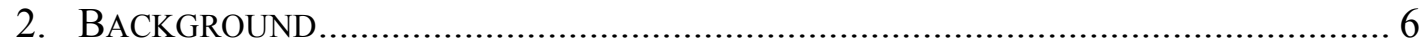

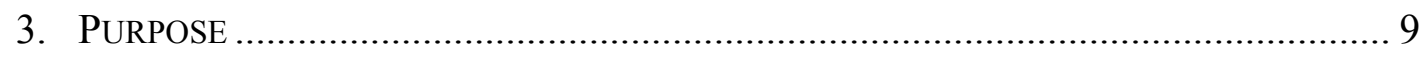

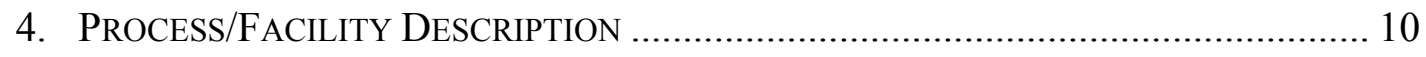

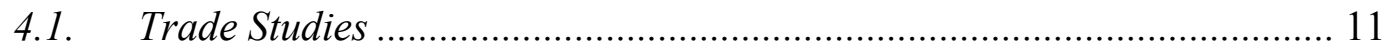

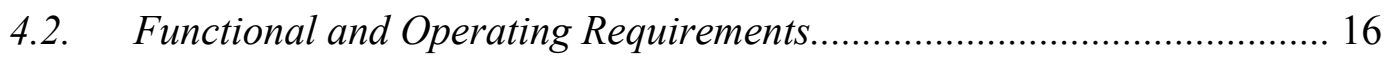

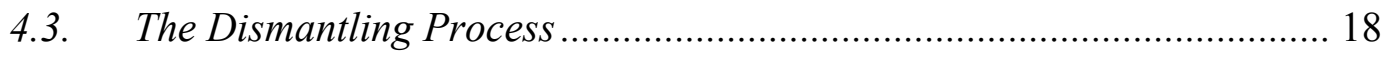

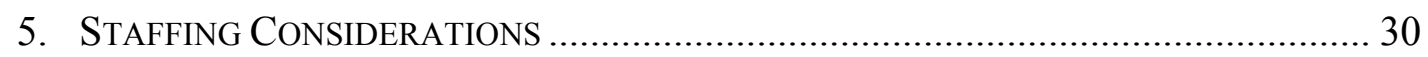

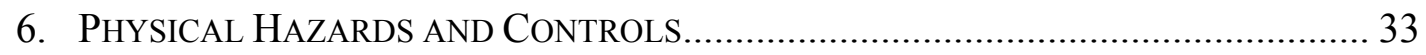

6.1. Material Handling and Pinching/Crushing Hazards ............................. 34

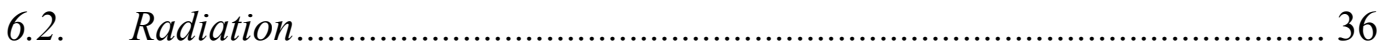

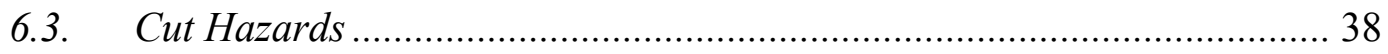

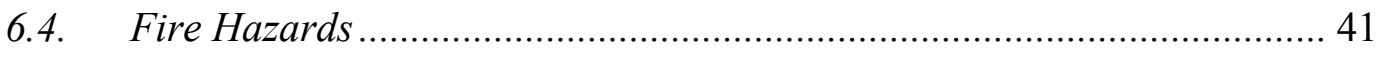

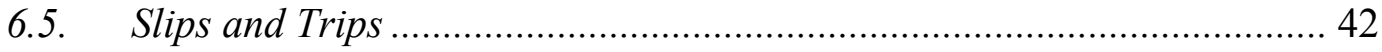




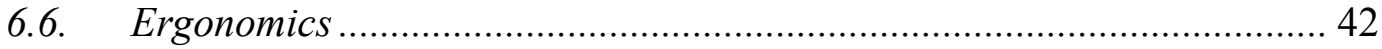

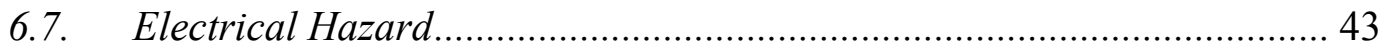

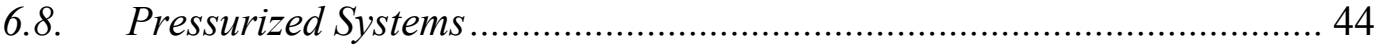

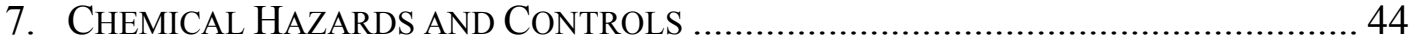

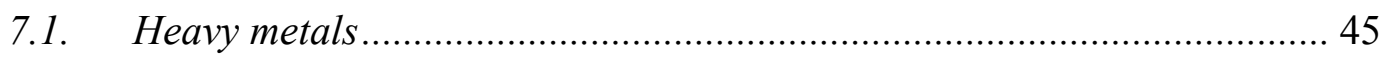

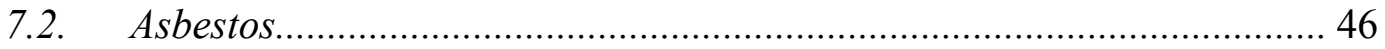

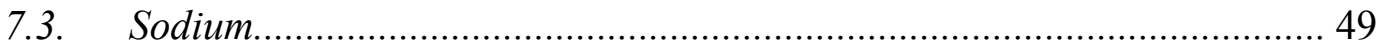

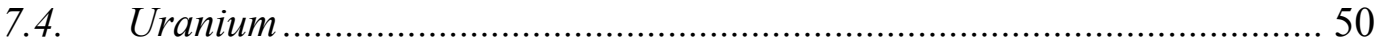

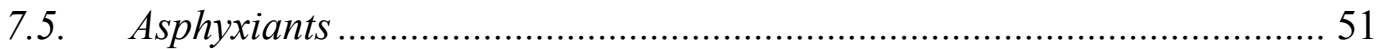

8. MoCK-UP AND READINESS ASSESSMENTS ................................................ 51

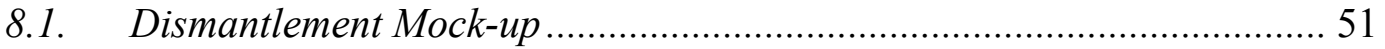

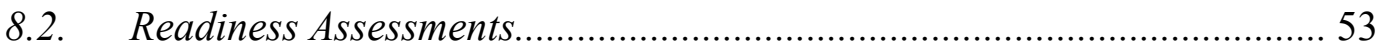

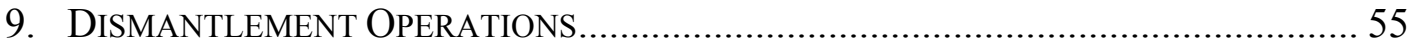

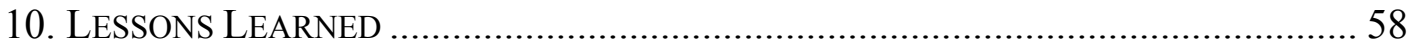

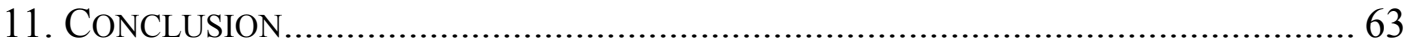

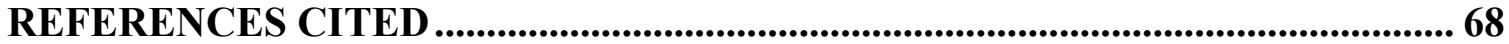




\section{List of Tables}

Table I. Applicable Experimental Assembly Dismantlement Safety and Health Regulations...17

Table II. Experimental Assembly Dismantlement Activities and Worker Resources................30 


\section{List of Figures}

Figure 1. Loading face of the Clementine fast neutron reactor at Los Alamos National

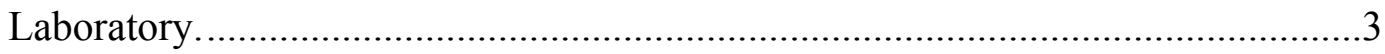

Figure 2. Experimental Breeder Reactor-I located near Arco, Idaho. ..............................4

Figure 3. Four lights bulbs powered by Experimental Breeder Reactor-I on December 20, 1951.

Figure 4. Photograph and radiograph of a typical SNL sodium debris bed experimental assembly.

Figure 5. Proposed location for sodium debris bed experimental assembly dismantlement showing floor pit requiring modification. 12

Figure 6. Construction of the SNL experimental assembly dismantlement containment tent

Figure 7. Dismantling containment tent floor plan. 15

Figure 8. Portable storage units for both the short and long SNL experimental assemblies

Figure 9. Containers associated with the SNL experimental assembly dismantling process.

Figure 10. A typical clamshell lathe proposed for use to support the Russian doll dismantling method

Figure 11. Mock-up showing transfer of an experimental assembly into the dismantlement containment tent

Figure 12. Containers associated with the SNL experimental assembly dismantling process 
Figure 13. Alternatives for stands for the transport and storage of the ISC. Option 4 was selected as the preferred option. 28

Figure 14. Flow diagram for SNL experimental assembly dismantlement. 29

Figure 15. A tent hoist and spreader bar are used to lower the experimental assembly onto the dismantlement work table 35

Figure 16. Illustration of the containment tent work table with band saw, slitting jointer, and pipe holding and rotating fixture. 40 


\section{Acronyms}

$\begin{array}{ll}\text { AEC } & \text { Atomic Energy Commission } \\ \text { ANL } & \text { Argonne National Laboratory } \\ \text { CFR } & \text { Code of Federal Regulations } \\ \text { DOE } & \text { (United States) Department of Energy } \\ \text { EBR-I } & \text { Experimental Breeder Reactor-I } \\ \text { IDAPA } & \text { Idaho Administrative Procedures Act } \\ \text { INL } & \text { Idaho National Laboratory } \\ \text { ISC } & \text { interim storage container } \\ \text { NRC } & \text { Nuclear Regulatory Commission } \\ \text { PCV } & \text { primary containment vessel } \\ \text { PPE } & \text { personal protective equipment } \\ \text { PSU } & \text { portable storage unit } \\ \text { Rem } & \text { Roentgen equivalent man } \\ \text { SNL } & \text { Sandia National Laboratory }\end{array}$




\section{Introduction}

Shortly after the Japanese bombing of Pearl Harbor on December 7, 1941, research into the production of plutonium for atomic weapons was initiated. The program was consolidated at the University of Chicago under Nobel Laureate Arthur H. Compton. At his facility, now known as Argonne National Laboratory (ANL), a small group of scientists, led by Enrico Fermi, built the world's first nuclear reactor, Chicago Pile-1. Chicago Pile-1 achieved initial criticality less than one year from the Pearl Harbor bombing, on December 2, 1942.

By early 1944, Compton, Fermi, and the other scientists in Chicago began to consider the role of their facilities after World War II. One suggestion from their discussions was to use nuclear fission to provide abundant power to cities across the United States. A primary concern was related to the scarcity of fissile material for nuclear fuel (Cochran et al, 2010). Fissile isotopes undergo fission when they absorb neutrons and, on average, release more neutrons than they absorb. This allows for a sustained chain reaction. The most important fissile materials for nuclear power reactions are uranium-235 and plutonium-239. At that time it was unclear whether there were sufficient uranium deposits available for atomic weapons production alone. As a result, Fermi's interest concentrated on means to generate maximum power with minimal source material. Processes that could provide nuclear material for weapons as a by-product of power production were especially desirable. These scientists recognized that plutonium-239 is created when uranium-238, which comprises 99.3 percent of natural uranium, absorbs a neutron. Furthermore, they found that certain reactor configurations could allow for the conversion of uranium-238 to plutonium at a rate faster than that at which fissile uranium-235 is consumed, leading to the term "breeder reactor." In order to promote the breeding of plutonium it is important to maintain energetic neutrons. This precludes the use of water as the primary reactor 
coolant, as is the case for a light water reactor, since the hydrogen in the water significantly slows released neutrons. This prevents plutonium from being generated at a rate that exceeds the consumption of uranium-235. Energetic, or fast, neutrons produce more secondary neutrons per fission with plutonium-239 than any other isotope (von Hippel, 2010). Therefore, a different coolant was required to promote this type of reactor technology. The coolants of choice focused on metals with relatively low melting points. These were ideal since liquid metals tend to be good heat conductors, thus allowing the heat in the reactor core to be quickly dissipated.

The world's first fast-neutron reactor was constructed at the Omega Site in Los Alamos, New Mexico. Clementine was a twenty-five kilowatt thermal, mercury-cooled experimental reactor (see Figure 1). It was proposed and approved in 1945. Construction of the Clementine reactor began in August 1946 and criticality was quickly achieved before the end of the year. Clementine reached full-power operation in March 1949. The reactor was shut down temporarily in 1950 and permanently in 1952 due to ruptured fuel rods that contaminated the mercury coolant. As a result of measurements made during operation of the Clementine reactor and evaluation of the failure modes, researchers learned that the heat transfer properties of mercury were not appropriate for use as a coolant in fast reactors (Bunker, 1983). Moving forward, most fast reactors utilized metallic sodium-based coolant materials. 


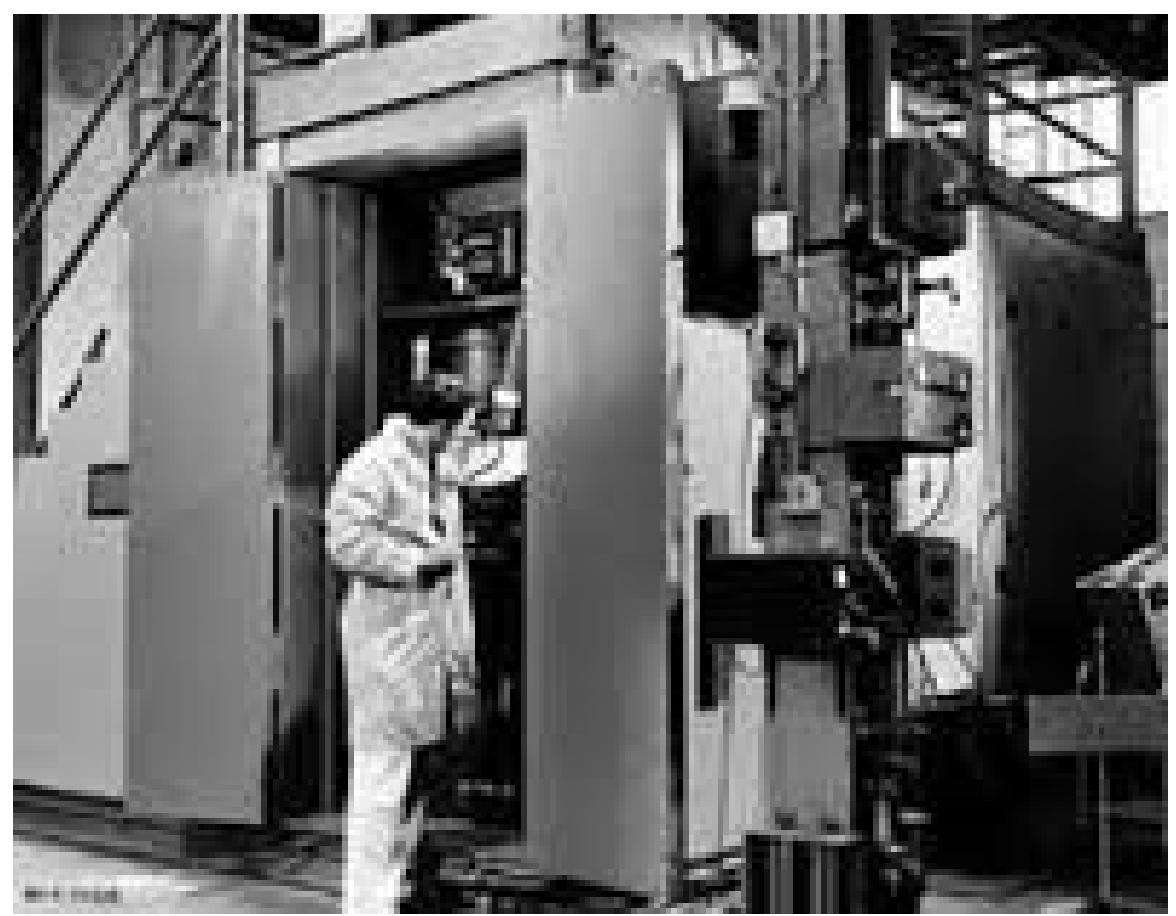

Figure 1. Loading face of the Clementine fast neutron reactor at Los Alamos National Laboratory (The future of Things, 2006).

In 1946, the newly formed Atomic Energy Commission (AEC) was given authority over all nuclear research in the United States. The entire reactor program was consolidated at the Argonne National Laboratory in Chicago under the direction of Walter Zinn. The AEC's interests included reactors to produce plutonium for weapons, the production of radioisotopes for medicine and general research, and also to support widespread public interest in using reactors to generate electricity for power. Early on, Enrico Fermi and Walter Zinn discussed the possibility of developing a fast reactor that could breed plutonium from uranium. From their collaboration came the design of Experimental Breeder Reactor-I (EBR-I) (Frost, 1996) (see Figure 2). Authorization to design and build the liquid metal-cooled, fast neutron reactor was issued by the AEC in November 1947. The design team elected to utilize a sodium-potassium alloy as the coolant for the reactor core. Complicating the design was the decision to cool the control rods with air due to concerns that the sodium potassium alloy might cause the control rods to stick or 
corrode. Since the sodium-potassium liquid metal burns in both water and air, the air and metal cooling systems were required to be completely separated and leak-proof.

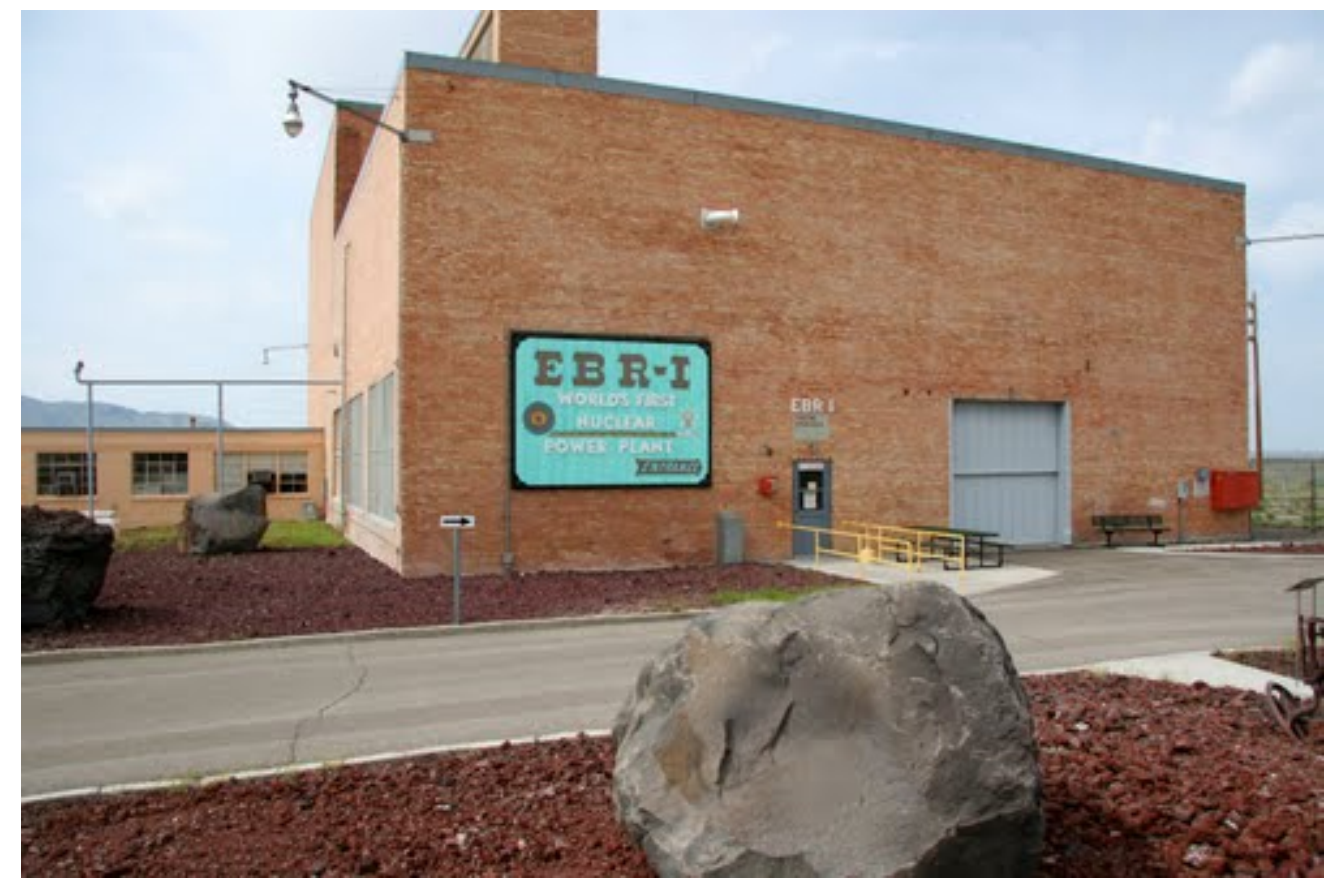

Figure 2. Experimental Breeder Reactor-I located near Arco, Idaho (Panoramio).

Due to public safety concerns associated with building nuclear reactors in the heavily populated Chicago area, Zinn requested that the AEC identify a remote site for EBR-I. The commissioners selected a location near Arco, Idaho, in the southeastern portion of the state, which had served as a proving ground for navy ordnances during World War II. The location came to be known as the National Reactor Testing Station, but is now part of the Idaho National Laboratory (INL). The 1.2 megawatt electric reactor went critical on December 20, 1951, and when it successfully lit four 200-watt light bulbs, it became the world's first electricitygenerating nuclear power plant (see Figure 3). 


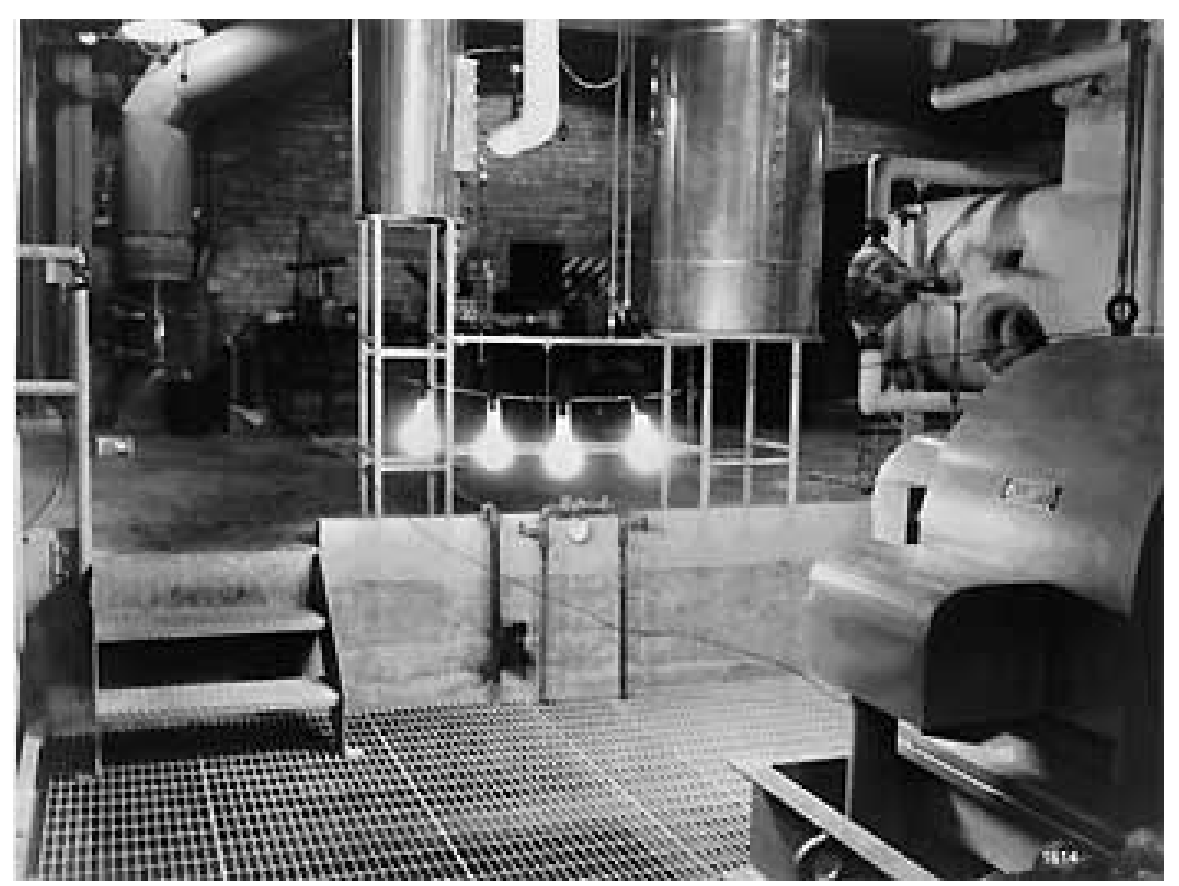

Figure 3. Four lights bulbs powered by Experimental Breeder Reactor-I on December 20, 1951 (European Nuclear Society).

On June 4, 1953, the AEC formally announced that EBR-I had become the world's first nuclear reactor to demonstrate the breeding of plutonium at a rate faster than the consumption of its enriched uranium fuel source. One undesirable condition that was found to be associated with EBR-I was that an increase in the temperature increased reactivity in the core. This is undesirable from an accident control perspective since less reactivity at increasing temperatures would tend to be self-controlling during high-temperature or loss-of-coolant scenarios. In order to support the design of future breeder reactors, EBR-I was used to research reactor temperature excursions and appropriate shut-down procedures. In November 1955, while conducting an experiment that raised the core temperature to obtain information about nuclear reaction instability, the reactor experienced a partial core meltdown. Approximately $50 \%$ of the core was lost as a result (Ragheb, 2010). The damaged core was replaced and the repaired reactor operated until December 30, 1963. The accident at EBR-I focused attention and subsequent research on the potential safety issues associated with fast-neutron reactors. Of particular concern was the 
possibility of an explosive criticality due to incomplete or ineffective cooling that could result in melting and collapse of the core, forming what was referred to as a debris bed, or sodium debris bed in the case of a sodium-cooled reactor.

Statutory authorization to proceed with the first liquid metal fast breeder reactor demonstration plant was obtained in 1969. The facility was sited at a bend in the Clinch River on the AEC site at Oak Ridge, Tennessee. Not surprisingly, the facility came to be known as the Clinch River Breeder Reactor. The goal was to act as a bridge between the smaller reactors built previously and an eventual full-size prototype commercial reactor. The facility was expected to provide electricity to the existing Tennessee Valley Authority electrical distribution grid to demonstrate the concept of breeder reactor use for commercial power production. The reactor was a sodium loop-cooled breeder utilizing fuel comprised primarily of uranium oxide.

Beginning in 1972, the Liquid Metal Fast Breeder Reactor Program, and particularly the Clinch River Breeder Reactor, became the focal point of public and political opposition due to economic, nonproliferation, and safety concerns. On March 24, 1977, President Jimmy Carter, ordered the indefinite deferral of commercial nuclear fuel reprocessing in the United States. In the same directive, President Carter suspended the licensing process for the Clinch River Breeder Reactor (Coleman, 2009).

\section{Background}

Concerned about the potential for fuel materials and thermal insulation to melt and collect within the reactor vessel, forming a debris bed, during temperature excursions or loss of coolant events, the Nuclear Regulatory Commission (NRC), the successor to the AEC, coordinated many experiments to determine the impact of debris beds both in water and liquid metal-cooled reactors. Since fission products associated with the debris beds can evaporate the 
water or liquid metal coolant, it is crucial to continue to cool debris beds to the extent possible to prevent or limit damage to the nuclear fuel elements (Ragheb, 2010). Beginning in the mid1970s, and continuing through 1985, Sandia National Laboratory (SNL), a United States Department of Energy (DOE)-owned research facility, conducted a series of experiments for the NRC to determine how nuclear reactor debris beds that could be formed during accident scenarios could be effectively cooled passively via nuclear reactor assembly design features.

Eleven experimental assemblies were constructed at SNL to simulate debris beds formed in a sodium-cooled fast breeder reactor. The experimental assemblies contained enriched uranium oxide fuel in a crucible that is integrally mixed with up to five kilograms of metallic sodium in a coolant bed. The crucible and sodium bed were enclosed in a cylindrical primary containment vessel (PCV) comprised of either Inconel or stainless steel. The PCV with external thermal insulation was then placed into a cylindrical secondary containment vessel made of stainless steel (see Figure 4). The assemblies also include integral instrumentation to measure temperature, pressure, and other parameters of concern during testing. Parameters such as sodium bed height, particle size, stratification, and location of thermal insulation were varied to account for anticipated debris bed formation and cooling scenarios. 


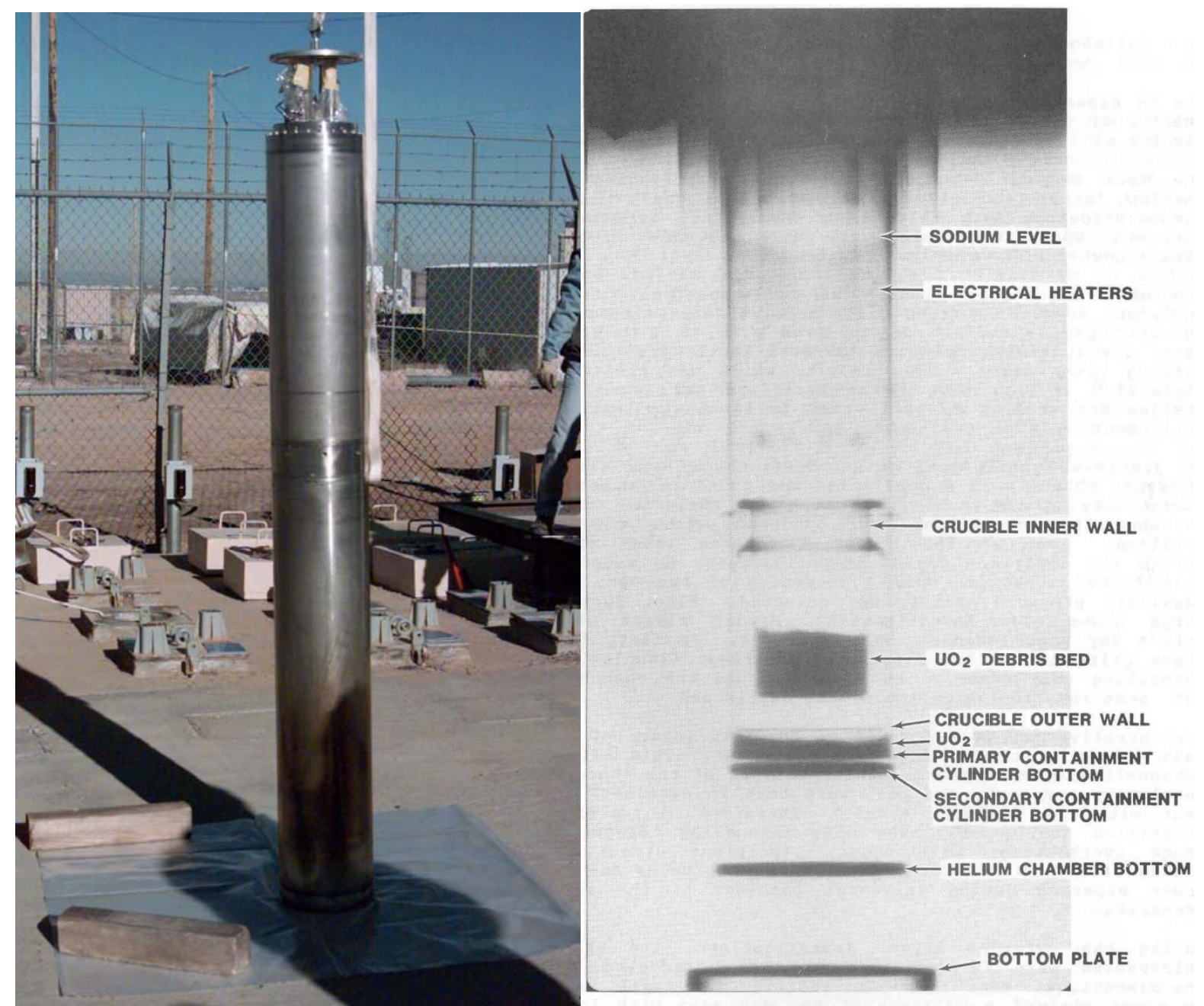

Figure 4. Photograph and radiograph of a typical SNL sodium debris bed experimental assembly (Croft, 2013).

The diameter of the outermost container ranges from approximately six to nine inches.

The length of the assemblies varies from twenty-three to seventy-five inches. Ten of the eleven experimental assemblies were slightly irradiated, resulting in up to a $1 \mathrm{Rem} /$ hour dose rate on contact as of February 2006 (Trinh and Barth, 2006).

During 2007 and 2008 the eleven sodium debris bed experimental assemblies were transferred to INL within individual shipping canisters and portable storage units (PSUs) for storage, disassembly, uranium recovery, and waste treatment and disposal. Management of the assemblies was divided into two phases: 1) dismantlement, and 2) recovery and disposition. This report evaluates the health and safety considerations associated with dismantlement of the 
secondary containment vessel, and recovery and safe storage of the PCV, which contains the uranium oxide fuel and metallic sodium bed.

\section{Purpose}

The goal of the INL Sodium Debris Bed Material Treatment Project is to disassemble the SNL sodium-bonded fuel experimental assemblies, recover the reusable uranium product, and treat and properly dispose associated waste. The benefits of this project are threefold in that: 1) it provides for the recovery of the enriched uranium in each experimental assembly so that it may be potentially reintroduced as raw material into the commercial nuclear fuel production cycle; 2 ) recovery and proper control of the nuclear material addresses nuclear proliferation concerns; and 3 ) it ensures proper segregation and disposal of waste materials to alleviate environmental concerns associated with long-term storage (Conceptual Design Report for Sandia Sodium Debris Bed Material Treatment, 2011).

As described previously, management of the SNL experimental assemblies will occur in two phases at INL. The first phase is termed dismantlement and includes the following activities:

- Transfer of the eleven assemblies within their individual PSUs from their temporary storage location to the disassembly area.

- Dismantle each assembly, one-at-a-time, down to the PCV.

- Package the PCV into an interim storage container (ISC).

- Move the ISCs to a temporary storage location until such time as the recovery and disposition phase is ready to proceed.

- Decontaminate and disassemble the dismantlement equipment that is no longer required.

- Properly dispose of any accumulated waste materials. 
Planning and design of the dismantlement process was initiated in 2010. Mock-ups and readiness self-assessments took place from 2013 through 2014 with physical disassembly operations commencing in late 2014 .

The INL Sodium Debris Bed Material Treatment Project was divided into two phases primarily due to the time required to design and test equipment necessary for the separation of integrated metallic sodium from the uranium oxide fuel within the PCV. The goals of the recovery and disposition phase of the project are to utilize a thermal vacuum distillation process to separate the sodium from the reusable uranium product, package and transfer the uranium to a facility that will allow it to reenter the nuclear fuel cycle, and treat or dispose of all waste recovered from the experimental assemblies, including the reactive sodium, metals from the assembly structure and instrumentation, and low-level radioactive materials. The recovery phase of the project is anticipated to begin as early as 2016 .

\section{Process/Facility Description}

In order to begin the planning process for the experimental assembly dismantling phase of the project two parallel tasks were initiated. These were to: 1) identify the appropriate personnel from a variety of affected disciplines and begin a series of trade study meetings to identify dismantlement options; and 2) identify and document all appropriate functional and operating requirements including design and construction standards, electrical and structural codes, safety requirements, and waste management regulations. Organizations participating in the trade study planning sessions included Facility Operations, Project Management, Financial Controls, Engineering, Maintenance, Planning and Scheduling, Safety, Industrial Hygiene, Environmental, Radiological Controls, Nuclear Safety Analysis, Criticality Safety, Quality Assurance, Safeguards and Security, Waste Management, Packaging and Transportation, 
Emergency Management, Document Control, Supply Chain, Training, and Contractor Oversight (Project Execution Plan, 2012). A series of trade study work sessions were conducted over a three-month span to identify alternatives for disassembling the experimental assemblies down to the PCV and temporarily storing the vessels. These trade studies included the identification of facilities, personnel, equipment, instrumentation, and the disassembly methodology required for dismantlement.

\subsection{Trade Studies}

Eight facilities at INL were identified as possible locations to complete the dismantlement activity. These were narrowed down to one based upon criteria developed in early trade study meetings. The location-defining criteria included available space, competing processes, meeting appropriate hazard and safeguards facility design criteria, proximity to adequate nuclear material storage locations, existing security personnel and equipment, and anticipated cost of facility modifications. The preferred location met all the criteria identified above, had minimal competing processes for the identified space, and only required one physical modification to the facility. The cell is approximately 20 -ft high and includes a 5 -ton-capacity polar crane with a maximum hook height of 17 feet 2 inches. The modification required for the facility involved the presence of a 45-inch-deep pit occupying a floor area of approximately $17 \times 35$ feet.

Perpendicular to the pit area is a 7 -foot wide and 2-1/2-foot deep trench. These areas would need to be filled with concrete or otherwise modified to provide a level surface at ground level (see Figure 5). During the trade study meetings it was determined that in order to maintain flexibility within the facility, the floor pit and trench would be covered using a removable false floor. The floor is composed of structural steel columns, beams, grating, and decking. The floor has a live load capacity of $1,500 \mathrm{lb} / \mathrm{ft}^{2}$ and can accommodate a 6,200-lb loaded vehicle, such as a forklift. 


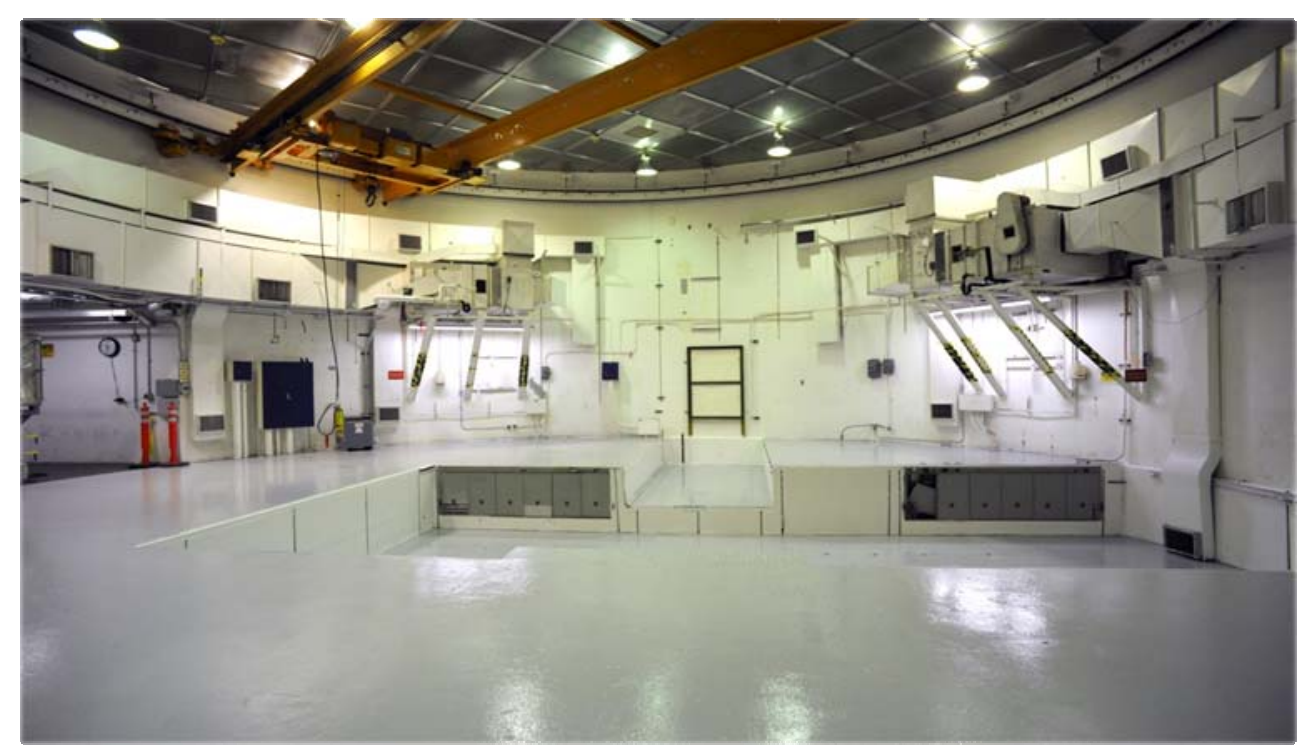

Figure 5. Proposed location for sodium debris bed experimental assembly dismantlement showing floor pit requiring modification (Conceptual Design Report for Sandia Sodium Debris Bed Material Treatment, 2011).

As a result of the radiological nature of ten of the eleven sodium debris bed experimental assemblies, there was a great deal of discussion during the trade study meetings regarding the appropriate level of radiological containment to safely dismantle the units. Radioactive elements of concern included not only the uranium fuel itself, but also trace fission or activation products associated with irradiation of the assemblies and contamination of the metallic sodium, thermal insulation, or other components. In addition, concern was expressed regarding other hazardous materials present within the assemblies that justified the selection of containment devices. As described previously, the crucible containing the enriched uranium oxide fuel is covered by an integral metallic sodium bed. Although the uranium and sodium are located within the PCV, one early assumption for dismantlement phase planning and design is that the primary containment is considered to be breached. This was done since the experimental assemblies were exposed to thermal cycling and irradiation that could have compromised the primary containment. It ensures adequate planning is performed to address the potential presence of metallic sodium, which is reactive in both air and water. The thermal insulation in five of the experimental assemblies also 
was identified as asbestos-containing material. As such, the preferred methodology would minimize disturbance of the insulation and provide controls to contain any friable asbestos. During early trade study planning there was also concern about the potential for beryllium to be present in components of the instrumentation present within the assemblies. The presence of beryllium was later eliminated as a concern following a review of SNL data on the eleven assemblies (Trinh and Barth, 2006).

This degree of planning allows for the incorporation of the preferred hierarchy for selecting safety and health controls: engineering, administrative, and personal protective equipment (PPE). Since the selection of containment devices would drive the identification of PPE, emphasis was given to engineered solutions. Containment options presented included the use of large or multiple glove bags, a glovebox, a soft-sided containment tent, a hard-sided enclosure, or no containment whatsoever given adequate facility design and ventilation. Because of the multiple chemical and radiological hazards, the option to forego containment was quickly eliminated. The use of glove bags or a glovebox was also eliminated due to the size of the experimental assemblies, which can reach up to approximately seven feet in length. In addition, the level of manual dexterity deemed necessary to effectively dismantle the assemblies made the use of glove bags or a glovebox impractical. The selection between a soft-sided containment tent versus a hard-sided enclosure was made based upon the cost and expected life cycle associated with each option since the level of protection offered by the two alternatives was deemed comparable. Use of the containment device is considered to be a one-time activity for the SNL experimental assemblies. A soft-sided large area containment tent was ultimately selected and designed in accordance with INL procedures. Some factors guiding this selection included: 1) no other use for the dismantlement containment device was identified; 2) vastly shorter fabrication 
time; and 3) significantly reduced overall cost (Laboratory-Wide Procedure, 2006). The softsided tent also allows for easy communication between the various disciplines inside and outside the tent when motorized equipment is not being operated. The containment tent was designed and constructed internally at the INL (see Figure 6).

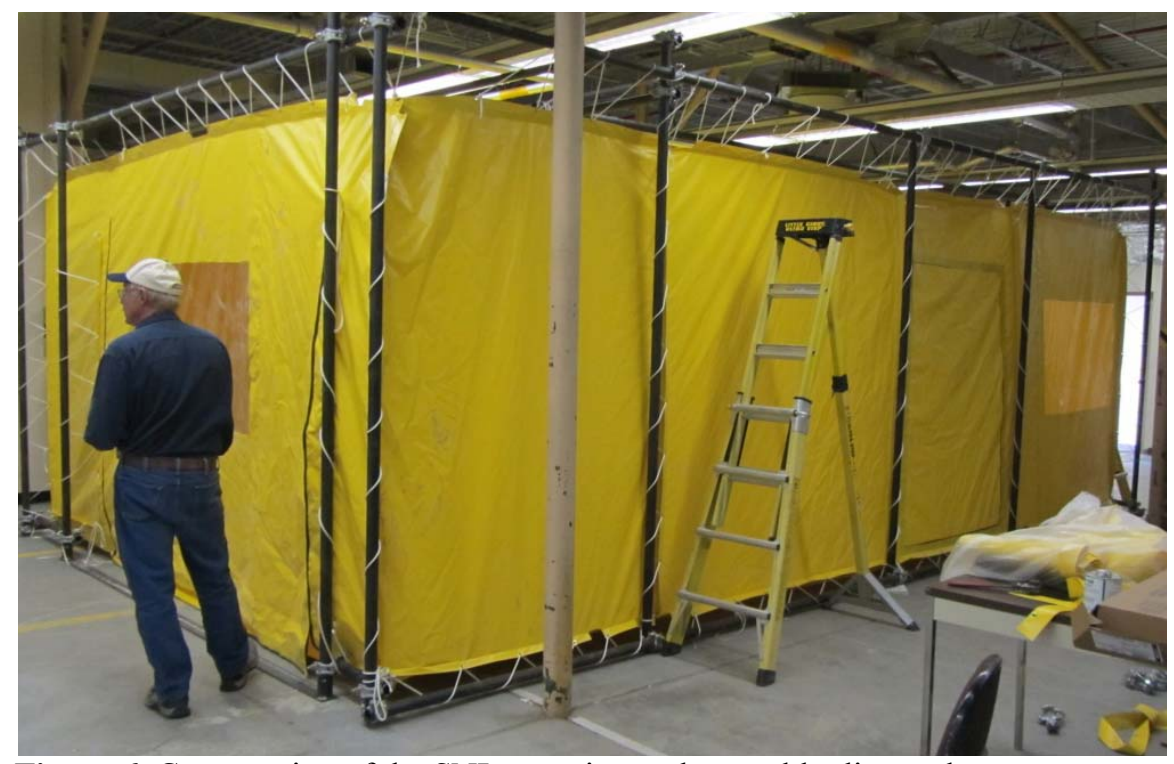

Figure 6. Construction of the SNL experimental assembly dismantlement containment tent (Croft, 2013).

The containment tent stands approximately $14 \times 18 \times 8$ feet and is designed for two operators and one radiological control technician to work inside it at one time. A roped off, stepoff (buffer) vestibule, large enough for two people plus radioactive or hazardous waste containers is provided, as well as an area where workers can don and doff PPE. An egress door is located on the opposite side of the tent from the personnel entrance. In addition, there is an opening for a waste box to be inserted into the tent in one corner. This allows for heavier waste to be lowered into a waste box inside the tent, reducing the potential spread of contamination. Radiological sensing equipment is stationed to identify any spread of contamination to the general cell area. The floor plan used for tent design is shown in Figure 7. 


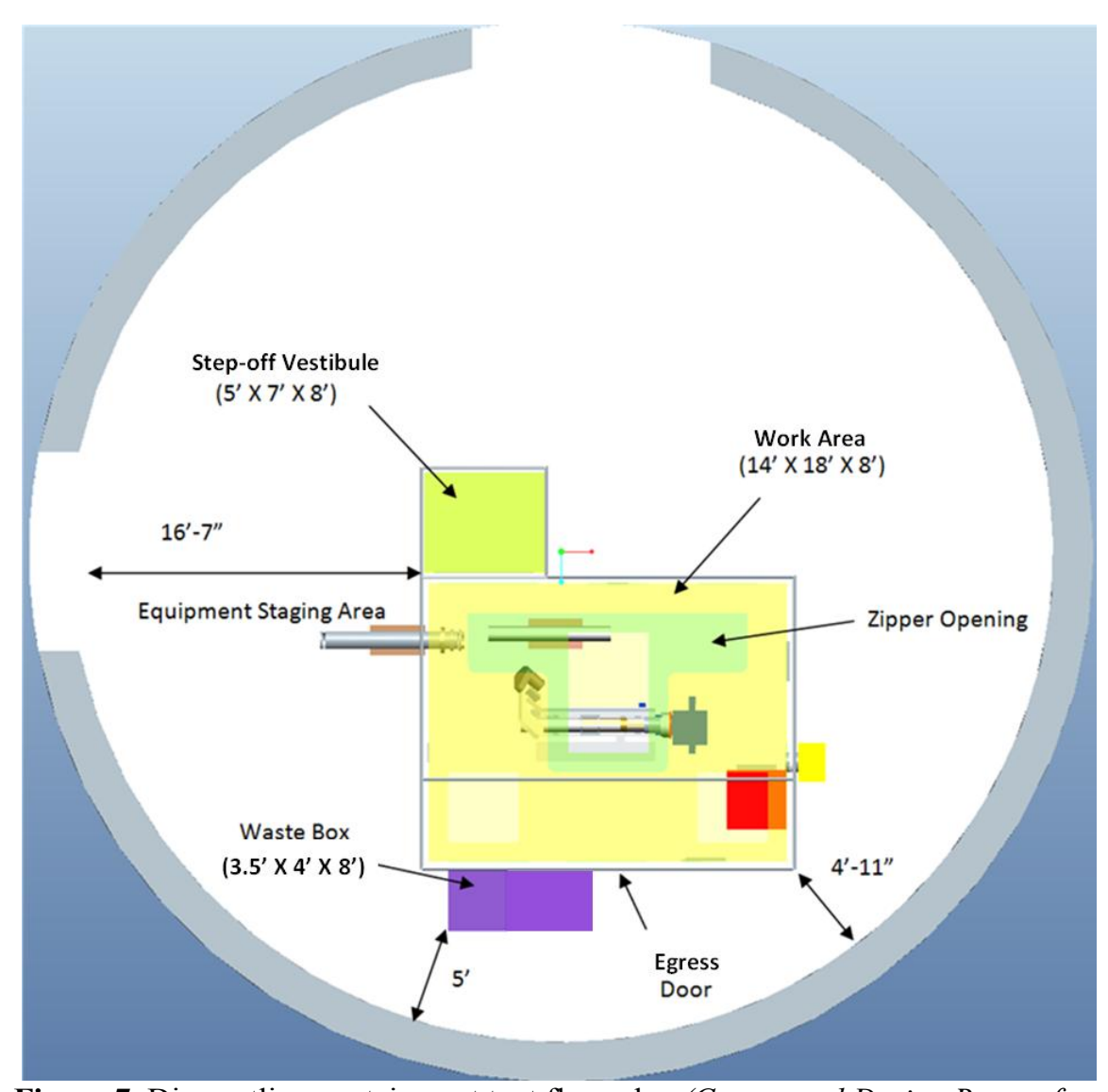

Figure 7. Dismantling containment tent floor plan (Conceptual Design Report for Sandia Sodium Debris Bed Material Treatment, 2011).

Windows are located around the tent to permit monitoring of activities from outside and to accept ambient light. Additional windows are located in the ceiling so that facility lighting can assist tent-installed fluorescent lighting inside the tent. The interior of the tent is ventilated by a high-efficiency particulate air (HEPA) filtration exhaust system. The HEPA filtration exhaust system is tied to the dismantling facility exhaust system, which is equipped with its own HEPA filter bank. The containment tent will meet negative pressure enclosure system requirements from the Occupational Safety and Health Administration for handling asbestos. As such, the HEPA filtration exhaust system will provide a minimum of four air changes per hour to maintain the airflow system and provide at least -0.02 column inches of water pressure differential relative to outside pressure in the containment tent (Occupational Safety and Health Administration, 
1996). The pressure differential will be monitored with a pressure gauge. A work table and tool box is provided inside the tent.

\subsection{Functional and Operating Requirements}

Development of the functional and operating requirements document was spearheaded by INL Engineering with support from all the organizations participating in the trade studies. The document identifies the applicable federal and state laws and regulations, and DOE directives. It further identifies INL-specific programmatic and procedural requirements as well as any applicable industry codes or standards. Finally, the functional and operating requirements document establishes specific performance criteria to be achieved within the design of the dismantlement equipment. Since much of the equipment to be utilized during the dismantlement phase of this project is off-the-shelf equipment, most of the specific performance criteria are related to the transfer of the experimental assembly or recovered PCV to or from the temporary storage location and the handling of heavy materials within the containment tent. Federal and State safety and health regulations identified in this document are provided in Table I below (Functional and Operational Requirements, 2011). 
Table I. Applicable Experimental Assembly Dismantlement Safety and Health Regulations

\begin{tabular}{|l|l|}
\hline \multicolumn{1}{|c|}{ Regulation } & \multicolumn{1}{c|}{ Source } \\
\hline Nuclear Safety Basis Requirements & $\begin{array}{l}\text { Federal - 10 Code of Federal Regulations } \\
\text { (CFR) 830 }\end{array}$ \\
\hline Occupational Radiation Protection & Federal - 10 CFR 835 \\
\hline Worker Safety and Health Program & Federal - 10 CFR 851 \\
\hline Resource Conservation and Recovery Act & Federal - 40 CFR 261-270 \\
\hline Facility Safety & Federal - DOE Order 420.1B \\
\hline Radioactive Waste Management Manual & Federal - DOE Manual 435.1-1 \\
\hline Nuclear Material Packaging Manual & Federal - DOE Manual 441.1-1 \\
\hline $\begin{array}{l}\text { Integrated Safety Management System } \\
\text { Manual }\end{array}$ & Federal - DOE Manual 450.4-1 \\
\hline Packaging and Transportation Safety & Federal - DOE Order 460.1C \\
\hline $\begin{array}{l}\text { Nuclear Material Control and } \\
\text { Accountability }\end{array}$ & Federal - DOE Manual 470.4-6 \\
\hline $\begin{array}{l}\text { Rules for the Control of Air Pollution in } \\
\text { Idaho }\end{array}$ & $\begin{array}{l}\text { State - Idaho Administrative Procedures Act } \\
\text { (IDAPA) 58.01.01 }\end{array}$ \\
\hline Rules and Standards for Hazardous Waste & State - IDAPA 58.01.05 \\
\hline INL Title V Air Permit & $\begin{array}{l}\text { State - Department of Environmental } \\
\text { Quality }\end{array}$ \\
\hline Quality
\end{tabular}

Other applicable safety requirements include industry requirements such as those established by the National Fire Protection Association, the American Society of Mechanical Engineers, and the American National Standards Institute, as well as company-specific standards 
including the INL Health and Safety Manual (Manual 14), the INL Nuclear Safety Manual (Manual 18), the INL Environmental Protection Manual (Manual 8), the INL Radiological Protection Manual (Manual 15), and the INL Waste Management Manual (Manual 17).

\subsection{The Dismantling Process}

The dismantling phase of the INL Sodium Debris Bed Material Treatment Project can be broken down into three elements. These are: 1) transfer the sodium debris bed fuel element experimental assemblies from temporary storage to the dismantlement location;2) dismantle the experimental assemblies to the PCV; and 3) repackage the PCV into an ISC and transfer the container back to a temporary storage location. Although it is apparent that the most obvious safety hazards are associated with the physical disassembly process, it is important to anticipate, recognize, evaluate, and control hazards present during all of these steps. Therefore, the dismantling process reviewed for this project includes all the steps associated with experimental assembly transfers, lifts, packaging, and waste collection, in addition to disassembly.

\subsubsection{Assembly Transfers}

Initial transfer activities require the movement of a single assembly, contained within its PSU (see Figure 8), from the temporary storage location to the dismantlement area. As described previously, the SNL assemblies differ in size by as much as five feet in length so it is not surprising that a variety of transfer methods were considered. While the shipping containers for the smaller assemblies are designed to hold the unit in a vertical orientation, the shipping containers for the larger assemblies can secure the unit in either a vertical or horizontal position. This was done since the longer assemblies may be stored vertically, requiring a smaller footprint, yet are transported horizontally, allowing for more stable movement. The storage containers are all free-standing. The primary equipment used for transferring the storage containers includes a 
forklift, for movement across uneven surfaces, a pallet jack, Rol-A-Lift pairs, and moving dollies. Adequate passages and doorways exist between the storage and dismantlement facilities for transportation by these means.
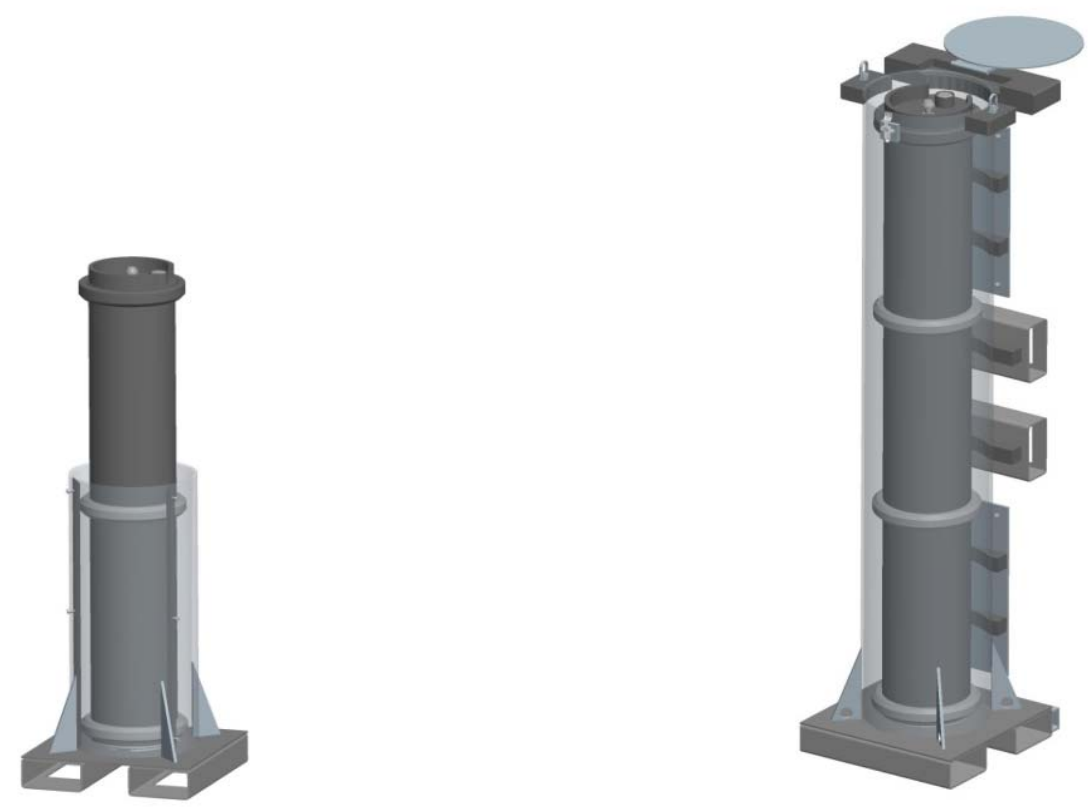

Figure 8. Portable storage units for both the short and long SNL experimental assemblies (Conceptual Design Report for Sandia Sodium Debris Bed Material Treatment, 2011).

After the PCV is recovered from each experimental assembly, it will be placed into an ISC that provides an additional robust confinement layer and allows for the addition of an inert atmosphere to prevent the reaction of sodium with air in the event of a breach of the inner containment. The ISC, in turn, is loaded into its own PSU. The PSUs will be transferred to a temporary storage location until the equipment required to separate the sodium from the enriched uranium oxide fuel has been assembled and tested. These PSUs will be transported using the same equipment identified for moving the assembly to the dismantling location. The storage and transfer containers used throughout the dismantling process are illustrated in Figure 9. 


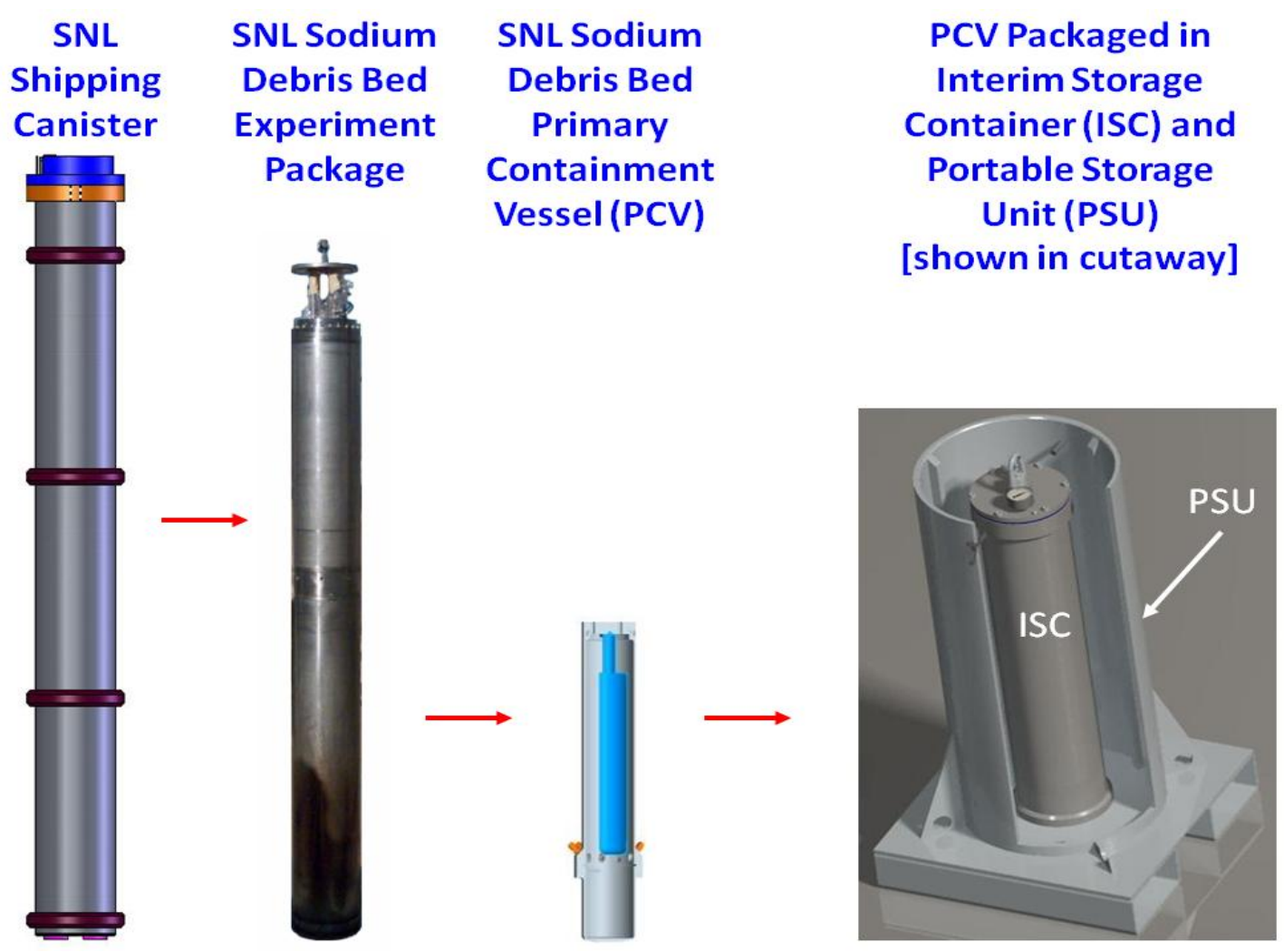

Figure 9. Containers associated with the SNL experimental assembly dismantling process (Conceptual Design Report for Sandia Sodium Debris Bed Material Treatment, 2011).

\subsubsection{Disassembly Process}

During the trade study meetings, which were held with participation from all affected disciplines, the team developed five disassembly alternatives for consideration. All of these alternatives build on an agreed upon work approach, comprised of a horizontal table and manual hand tools, from which to proceed. The options introduce additional capability as well as increased complexity and cost. The list of alternatives is provided below.

1. Russian doll method - With the experimental assembly held vertically in a positioning well, radial cuts would be made into successive layers of the assembly. The cuts would be made using a clamshell lathe (see Figure 10). Following each cut the severed layer would be removed to reveal the next lower layer prior to making a subsequent radial cut. Although this was determined to be the preferred method 
during the pre-conceptual design phase very early in the project, it was later determined that close tolerances between the nested layers would make this approach impractical.

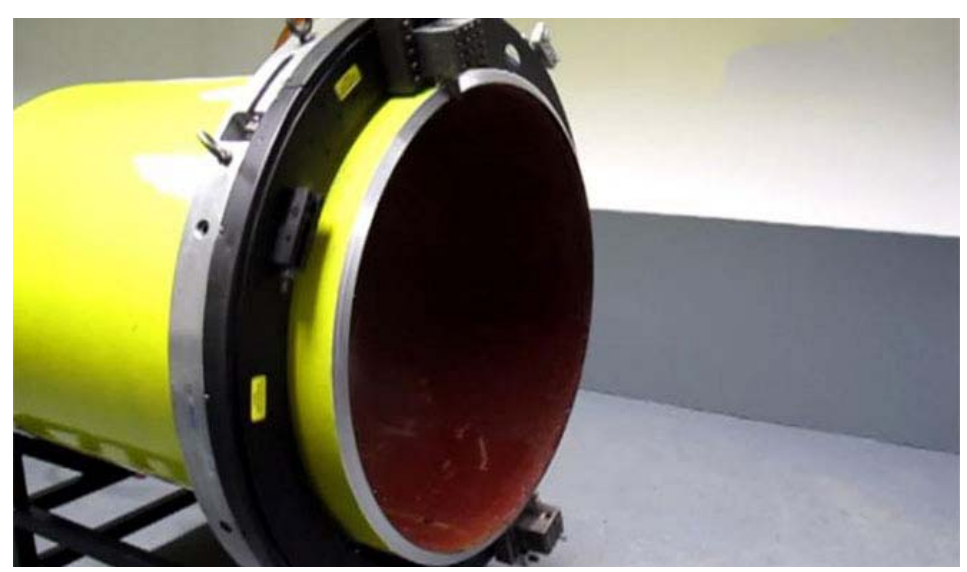

Figure 10. A typical clamshell lathe proposed for use to support the Russian doll dismantling method. (Mactech Europe Limited).

2. Hand tool method - This alternative would utilize a work table with minimal features along with a collection of hand tools to disassemble the experiments. Since some of the nested shells within the assembly are welded together, it was determined that this option, by itself, would not work. Moreover, due to concerns to maintain radiation exposure as low as reasonably achievable, manual cutting techniques are not generally preferred.

3. Machine radial cut method - This option builds upon the hand tool method by providing additional features to the work table to allow for securing and rotating experimental assemblies so that a motorized radial cutting tool could be used. This would allow radial cuts to be made more precisely and quickly, reducing radiation exposure to workers in close proximity to the assembly.

4. Machine radial and longitudinal cut method - This alternative provides additional capability by including means to complete longitudinal cuts in addition to radial cuts 
through the use of a motorized cutting tool. Since radial cuts alone were not expected to allow efficient removal of nested assembly layers, the ability to cut longitudinally was considered necessary.

5. Radial, longitudinal, and lop-off method - This final alternative provides capabilities from all the options above and adds the ability to complete through-cuts of the assembly. Initiating the dismantling process by lopping off the end above the sodium bed could make the remaining portion of the assembly more manageable.

The trade study team developed applicable "want" versus "must" criteria and associated weightings. Then, using an electronic decision analysis tool, the requirements for successful mission accomplishment were determined. The results indicated that dismantlement of the assemblies would require the use of manual power tools, hand tools, and fixed mounted power tools that can produce radial, longitudinal, and through-cuts, Alternative 5 from the list above. The analysis further determined that the work table needs to be capable of both horizontal and vertical positioning to aid in movement of the assemblies into or out of the containment tent.

Upon retrieving a PSU containing a sealed shipping canister with an experimental assembly from the temporary storage area and transferring it to the dismantling area containment tent, the shipping canister is unloaded using the existing facility crane. The canister can then be transported into the containment tent in one of two ways. The preferred method is to transport the shipping canister horizontally on a transfer cart and insert it through an engineered opening in the tent wall. A second option is to lower the canister into the tent through a closeable slot in the roof. Transfer carts placed both outside and inside the tent allow for easy transfer of the heavy containers. The opening in the side of the tent is equipped with a sleeve that is taped onto the shipping container while the container is cut open and the experimental assembly removed. 
In this way any radiological contamination is contained within the tent. After the experiment is unloaded, the outer shipping container is wiped clean and removed, and the sleeve sealed shut. This process is demonstrated in Figure 11. If the opening at the top of the tent is used to transfer the experimental assembly inside, the entire shipping canister is placed onto the work table.

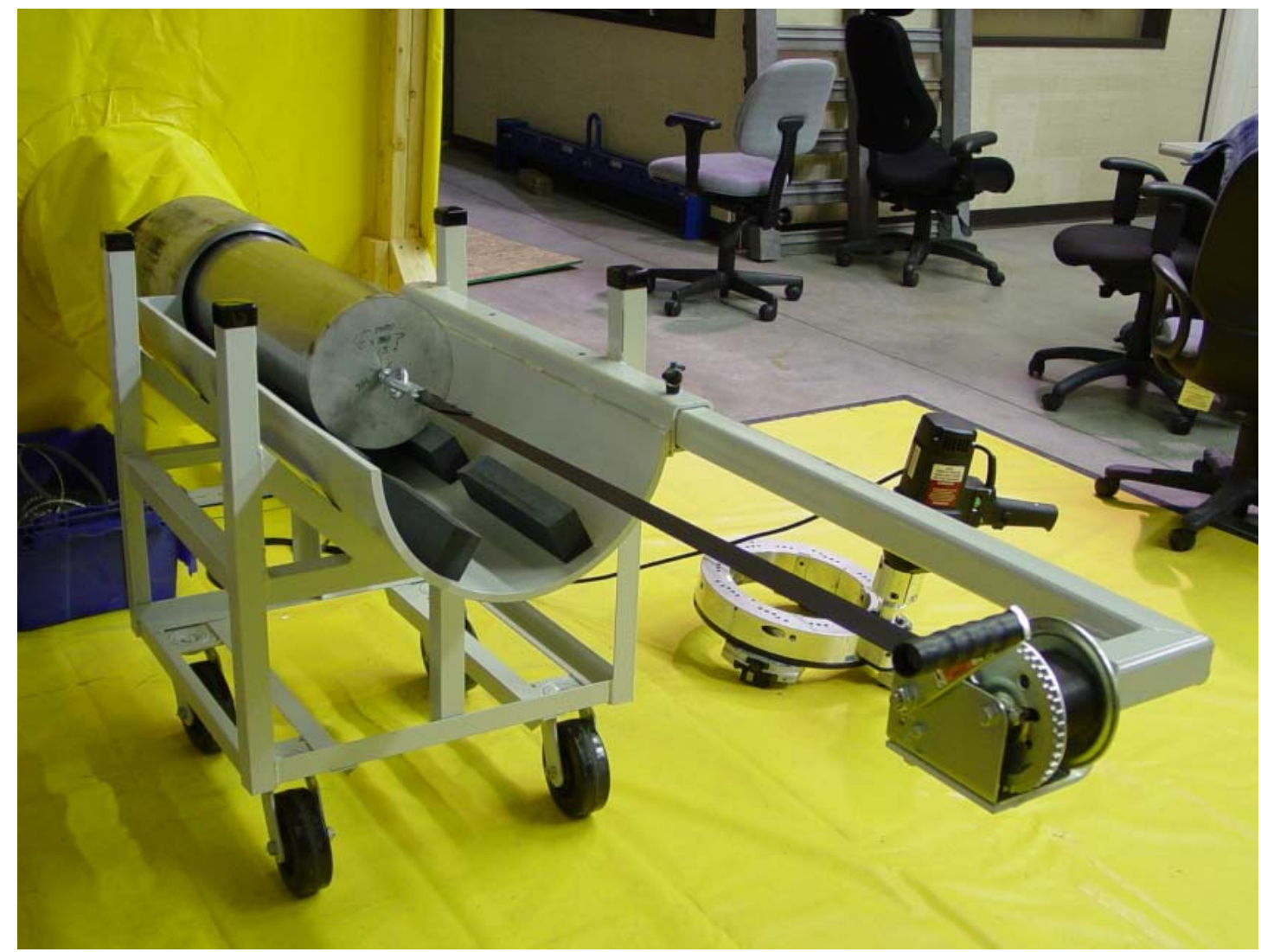

Figure 11. Mock-up showing transfer of an experimental assembly into the dismantlement containment tent (Croft, 2013).

In either case a specialized cutting tool, known as an outside-diameter split-frame clamshell tri-tool, is positioned around the head of the shipping canister to cut the $1 / 2$-inch thick canister wall, allowing removal of the container head. Figure 12 shows a tri-tool cutter being used in a similar cutting operation. After opening the shipping canister, the experimental assembly is removed with a ratchet and tent hoist and placed onto the work table. 


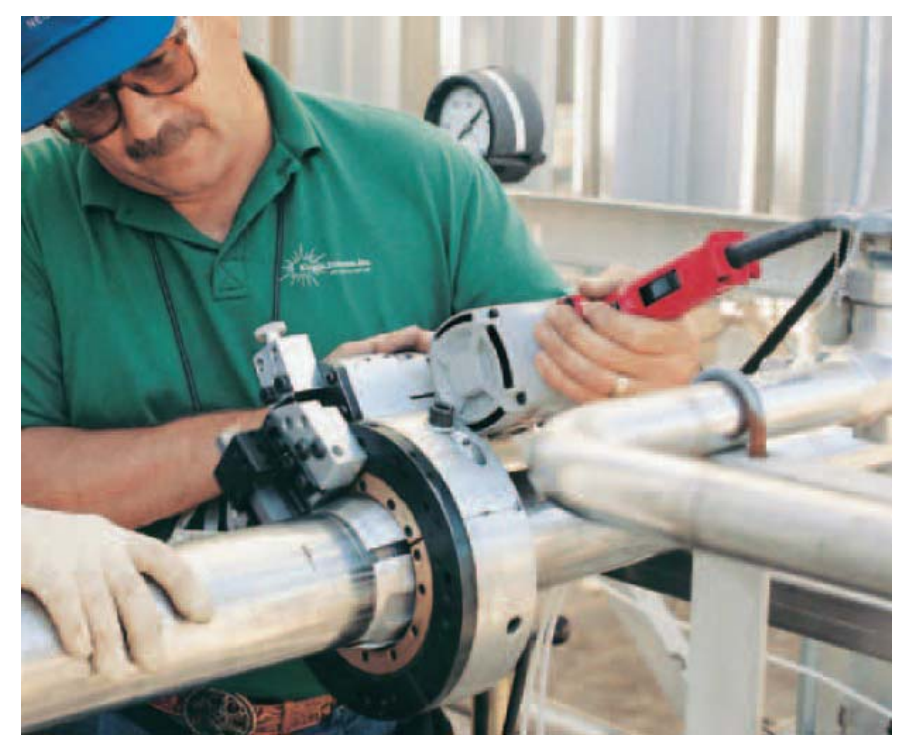

Figure 12. Containers associated with the SNL experimental assembly dismantling process (Conceptual Design Report for Sandia Sodium Debris Bed Material Treatment, 2011).

Due to variability in the construction of the eleven sodium-bonded fuel experimental assemblies, the dismantling process also varies slightly between some of the assemblies. The one assembly that was not irradiated is nothing more than a PCV in a shipping canister. In this case, the experimental assembly will be removed and placed directly into an ISC and PSU and relocated for temporary storage. Related to the other assemblies that were irradiated, the general procedure occurs as follows. The disassembly process begins by securing the assembly to the work table using a saddle fixture attached to a carriage on the table. Next, the assembly is opened by either unscrewing or drilling out fasteners from the face plate or lopping off the top end of the assembly with a band saw that is integrated into the work table. With the open end of the unit secured to a pipe bully, using the power-assisted table carriage the outer shell of the assembly is removed and disposed in a waste box. Once the outer shell is removed the inner layer of insulation may be removed by sliding it off the end of the assembly or carefully peeling it off. As described previously, five of the assemblies contain asbestos insulation while the remaining assemblies utilize non-asbestos-containing material. Next, subsequent inner shells and associated 
insulation are removed in the same way. Removing the inner metal shells may require throughcuts and/or circumferential cuts. Both types are performed with the band saw using the pipe bully to rotate the assembly, as needed. Longitudinal cuts are completed using a rail-mounted slitting jointer. Any wires, tubing, or instrumentation, such as thermocouples or pressure gauges, are removed along the way by unfastening them, when possible, or cutting through them. All wastes generated as a result of disassembly are collected into bags or waste boxes and segregated by waste type as waste without hazardous contaminants, asbestos-containing waste, sodium waste, low-level radioactive waste, or mixed (hazardous and radioactive) waste. If any uranium or sodium is encountered during disassembly, the workers are instructed to leave the area until the condition can be evaluated and appropriate mitigation planned. Once the PCV is revealed it is separated from any remaining insulation or monitoring instruments and removed. After being detached, the PCV is packaged into an ISC and placed into a PSU fitted with a spacer to accommodate the size of the vessel. The ISC is then purged and filled with argon to provide an inert atmosphere to prevent sodium reaction in case of a breach. Finally, the PSU containing the assembly PCV is transported to a temporary storage location (Technical Safety Requirements Procedure, 2015). This process is repeated for each of the experimental assemblies one-at-atime. All of the steps associated with this dismantling process are documented in an operating procedure that identifies prerequisites, task-specific hazards, controls, contacts, hold points, and appropriate documentation. This procedure ensures that the dismantling process occurs in a consistent, controlled manner, minimizing the number and duration of hazardous activities and reducing worker exposure times. 
During the trade studies a great deal of consideration was given to the determination of the assembly final processing order. Four factors were evaluated to make this determination. These included:

1) Experimental assembly complexity, which includes size, level of instrumentation, and manner of construction (i.e., the use of welds versus screws for fastening nested layers).

2) Similarities in construction of experimental assemblies - Excluding the nonirradiated assembly, the experimental assemblies were organized into three families or groupings, due to similarities in disassembly methodology.

3) Radiation dose rates using the estimated dose rate at contact for the unshielded PCV as of May 27, 2011 (Engineering Calculations and Analysis Report, 2011).

4) Presence of friable asbestos fibers in the insulation material - present in five of the experimental assemblies.

The potential presence of sodium outside the PCV was not considered in this evaluation since a breach of the primary containment was assumed for all the assemblies. The decision was made to dismantle the five assemblies containing friable asbestos last to avoid any potential of cross-contaminating the other assemblies, as well as to reduce the potential for worker exposure to asbestos. The remainder of the experimental assemblies was ordered based on complexity and similarity, with the lowest radiation dose rates first. By ranking dose rates within each of these complexity families, it is expected that as workers gain experience and familiarity from the disassembly of previous family members they will reduce disassembly times, and thus receive less exposure. 


\subsubsection{Repackaging of the Primary Containment Vessel}

Due to the anticipated delay between recovery of the PCV from the experimental assembly and readiness of the second phase of the project, sodium separation and uranium recovery, the planning team had to identify options for repackaging the recovered PCV into an ISC. Through meetings and discussion among various team disciplines, engineering personnel developed eight potential ISC configurations. These are listed below.

- Hard-sided container

- Bagged

- Enclosed in an air environment

- Inert atmosphere provided

- Place container/bag into existing storage racks

- Place container/bag into free-standing storage

- Place container/bag into new storage racks

- Design a unique storage holder for the PCVs.

The team concurred that the ISCs should allow for the addition of an inert atmosphere to prevent sodium reaction in the event of a breach of the PCV. This selection eliminated the possibility of using bags for interim storage since hard-sided containers are much less likely to be damaged or otherwise breached. The hard-sided containers are placed into the PSUs that were used for holding the shipping canisters in the previous temporary storage area. Spacers were constructed, as necessary, to fit within the PSUs to accommodate the ISC. Although a few new PSUs had to be constructed for some of the taller PCVs, reuse of the storage unit design was selected because it did not require preparation of a new design and it has already been 
seismically qualified per DOE requirements (United States Department of Energy, 2012). Some of the ISC stand designs are presented in Figure 13.

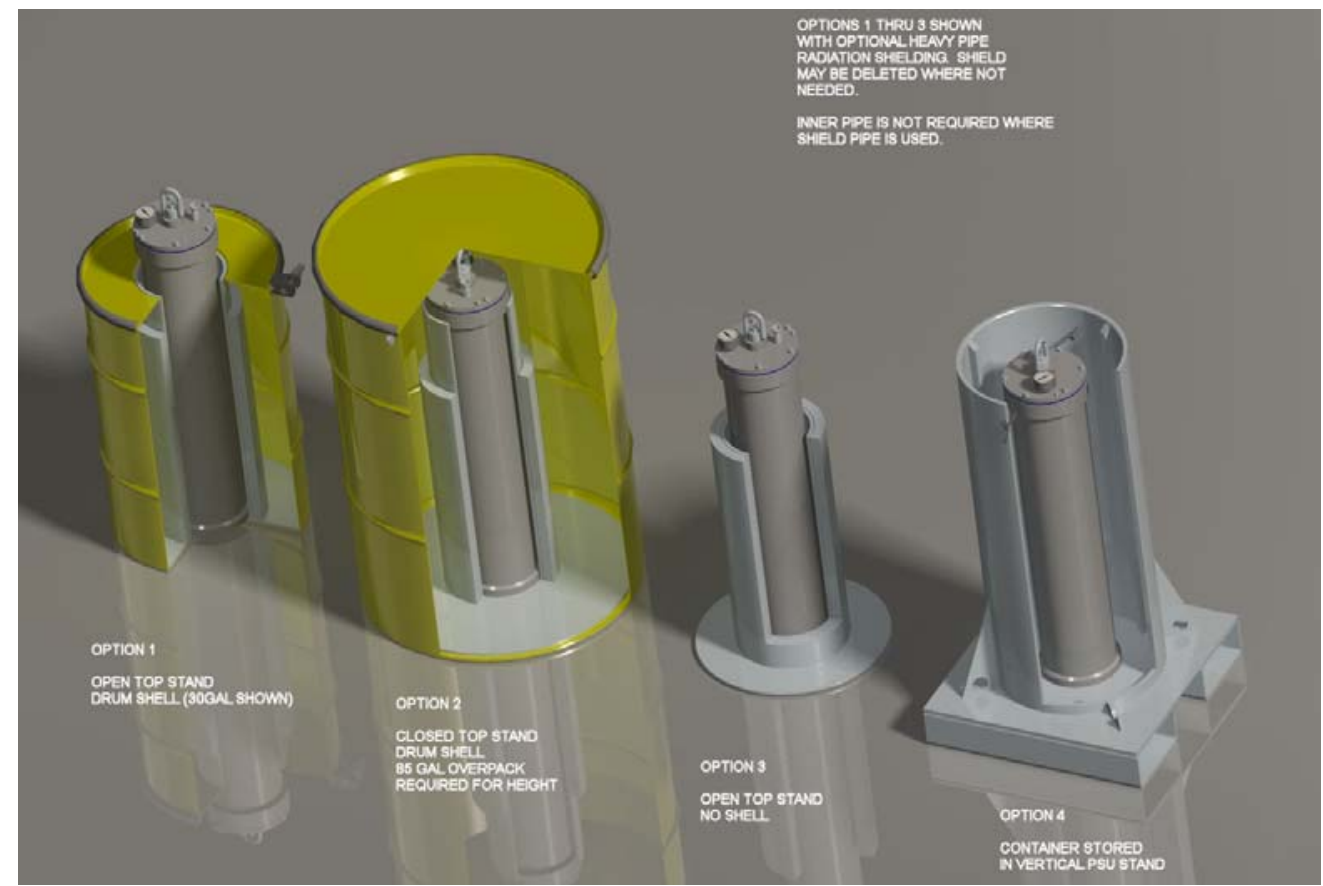

Figure 13. Alternatives for stands for the transport and storage of the ISC. Option 4 was selected as the preferred option (Conceptual Design Report for Sandia Sodium Debris Bed Material Treatment, 2011).

A process-flow diagram that shows the entire SNL sodium debris bed experimental assembly dismantlement processes, from transfer of the shipping canister to the dismantlement area through repackaging and storage of the recovered PCV, is presented as Figure 14. Details associated with the disassembly of specific experimental assemblies are not included in the flow diagram as unique construction characteristics of certain assemblies require different disassembly methods than for other assemblies. Moreover, the hazards associated with different assemblies dictate varying disassembly techniques, including the addition or removal of specific controls, such as those required for asbestos control. The processing order of the experimental assemblies has been assigned into similar families to allow operators to perform disassembly 


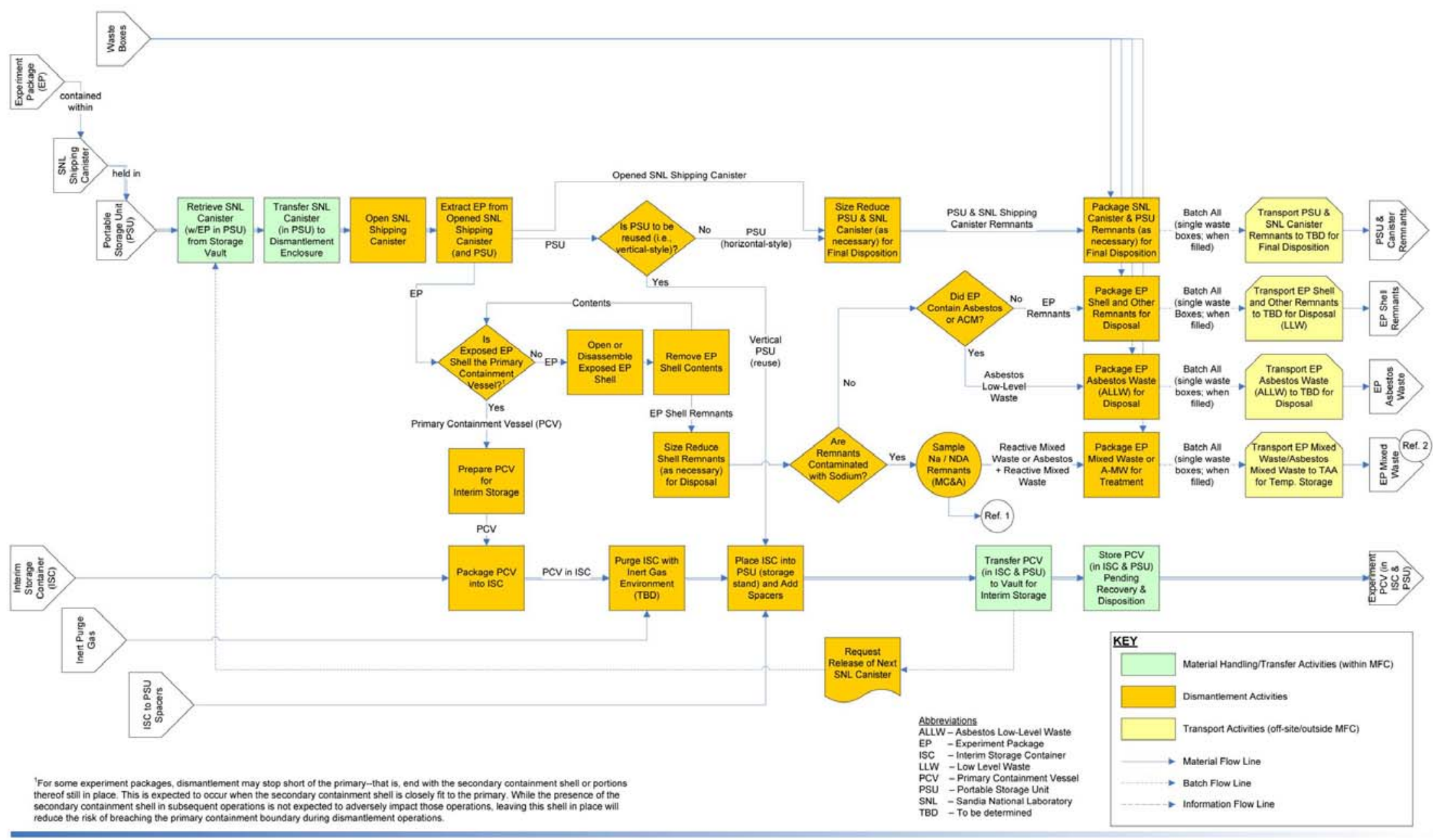

Figure 14. Flow diagram for SNL experimental assembly dismantlement (Conceptual Design Report for Sandia Sodium Debris Bed Material Treatment, 2011). 
techniques on similarly constructed assemblies consecutively with the least hazardous family member disassembled first. This allows the operators to learn, reducing worker exposure times.

\section{Staffing Considerations}

The bulk of activities associated with the dismantling phase of the INL Sodium Debris Bed Material Treatment Project are performed by facility operators. Many of these activities, however, are also supported by a variety of other INL personnel including laborers, heavy equipment operators, maintenance staff, industrial hygiene, industrial safety, radiological controls technicians, environmental waste management professionals, and nuclear safety/criticality control specialists. The INL field-deployed work force typically works ten hours per day, four days per week. The standard work day is considered adequate for performing the tasks associated with experimental assembly dismantlement. The INL work discipline type supporting each activity in the dismantlement phase is provided in Table II.

Table II. Experimental Assembly Dismantlement Activities and Worker Resources

\begin{tabular}{|l|l|c|}
\hline \multicolumn{1}{|c|}{ Activity } & \multicolumn{1}{|c|}{ Work Discipline } & Quantity \\
\hline Retrieve PSU from temporary storage area and & Facility Operator & 1 \\
transfer to the dismantlement facility & Laborer & 1 \\
& Equipment Operator & 2 \\
& Health Physics Technician & 1 \\
\hline Remove shipping canister from PSU & Facility Operator & 2 \\
& Industrial Safety & 1 \\
& Health Physics Technician & 1 \\
\hline Enter the containment tent & Facility Operator & 1 \\
& Health Physics Technician & 1 \\
& Industrial Hygiene (outside tent) & 1 \\
\hline Verify ventilation & Industrial Safety (outside tent) & 2 \\
& Facility Operator & 1 \\
& Health Physics Technician & 1 \\
& Maintenance & 1 \\
& Industrial Hygiene (outside tent) & 1 \\
\hline
\end{tabular}




\begin{tabular}{|c|c|c|}
\hline $\begin{array}{l}\text { Transfer shipping canister into tent, cut open } \\
\text { the end of the canister with the tri-tool, and } \\
\text { extricate experimental assembly placing it onto } \\
\text { the work table }\end{array}$ & $\begin{array}{l}\text { Facility Operator } \\
\text { Health Physics Technician ( } 1 \text { inside } \\
\text { tent / } 1 \text { outside tent) } \\
\text { Industrial Hygiene (outside tent) } \\
\text { Industrial Safety (outside tent) }\end{array}$ & $\begin{array}{l}2 \\
2\end{array}$ \\
\hline Remove shipping canister waste from the tent & $\begin{array}{l}\text { Facility Operator } \\
\text { Health Physics Technician ( } 1 \text { inside } \\
\text { tent / } 1 \text { outside tent) } \\
\text { Environmental (outside tent) } \\
\text { Industrial Hygiene (outside tent) } \\
\text { Industrial Safety (outside tent) }\end{array}$ & $\begin{array}{l}2 \\
2\end{array}$ \\
\hline $\begin{array}{l}\text { Disassemble experimental assembly, one } \\
\text { nested layer at a time, by unfastening or cutting } \\
\text { metal shells and removing thermal insulation } \\
\text { that may contain asbestos }\end{array}$ & $\begin{array}{l}\text { Facility Operator } \\
\text { Health Physics Technician } \\
\text { Industrial Hygiene (outside tent) } \\
\text { Industrial Safety (outside tent) } \\
\text { Environmental (outside tent) } \\
\end{array}$ & $\begin{array}{l}2 \\
1 \\
1 \\
1 \\
1\end{array}$ \\
\hline Expose, inspect, and remove PCV & $\begin{array}{l}\text { Facility Operator } \\
\text { Health Physics Technician } \\
\text { Nuclear/Criticality Safety (outside } \\
\text { tent) } \\
\text { Industrial Hygiene (outside tent) } \\
\text { Industrial Safety (outside tent) } \\
\text { Environmental (outside tent) }\end{array}$ & $\begin{array}{l}2 \\
1 \\
1\end{array}$ \\
\hline $\begin{array}{l}\text { Appropriately contain waste materials and } \\
\text { transfer out of the containment tent }\end{array}$ & $\begin{array}{l}\text { Facility Operator } \\
\text { Health Physics Technician ( } 1 \text { inside } \\
\text { tent / } 1 \text { outside tent) } \\
\text { Environmental (outside tent) } \\
\text { Industrial Hygiene (outside tent) } \\
\text { Industrial Safety (outside tent) }\end{array}$ & $\begin{array}{l}1 \\
1 \\
1 \\
\end{array}$ \\
\hline Repackage PCV into ISC & $\begin{array}{l}\text { Facility Operator } \\
\text { Health Physics Technician } \\
\text { Industrial Hygiene (outside tent) } \\
\text { Industrial Safety (outside tent) }\end{array}$ & $\begin{array}{l}2 \\
1 \\
1 \\
1\end{array}$ \\
\hline Remove ISC from the tent & $\begin{array}{l}\text { Facility Operator } \\
\text { Health Physics Technician ( } 1 \text { inside } \\
\text { tent / } 1 \text { outside tent) } \\
\text { Industrial Safety (outside tent) }\end{array}$ & $\begin{array}{l}2 \\
2\end{array}$ \\
\hline $\begin{array}{l}\text { Exit the tent, then purge and fill the ISC with } \\
\text { inert gas }\end{array}$ & $\begin{array}{l}\text { Facility Operator } \\
\text { Health Physics Technician } \\
\text { Industrial Hygiene } \\
\text { Industrial Safety }\end{array}$ & $\begin{array}{l}2 \\
1 \\
1 \\
1\end{array}$ \\
\hline Load the ISC into the modified PSU & $\begin{array}{l}\text { Facility Operator } \\
\text { Health Physics Technician } \\
\text { Industrial Safety }\end{array}$ & $\begin{array}{l}2 \\
1 \\
1\end{array}$ \\
\hline Transfer the PSU into temporary storage & $\begin{array}{l}\text { Facility Operator } \\
\text { Equipment Operator } \\
\text { Health Physics Technician }\end{array}$ & $\begin{array}{l}1 \\
2 \\
1\end{array}$ \\
\hline
\end{tabular}


The activities associated with disassembly of the debris bed experiments that are performed in the containment tent are limited by space and, as a result, required significant consideration regarding the logistics of personnel and equipment placement and the timing of necessary tasks. In order to reduce worker exposure to hazards associated with this effort, including radiation fields, radioactive contamination, asbestos, and heavy metals, the planning team intended to limit the number of workers in the containment enclosure to the smallest number practical, while still proving adequate staff to perform and monitor the work. The containment tent was equipped with windows to allow for personnel from supporting organizations to view work activities and communicate with employees inside the tent while maintaining radiological exposure as low as reasonably achievable. Personnel performing activities outside the tent include maintenance, industrial hygiene, safety, nuclear safety/criticality, environmental waste management, and radiological controls. In addition, firstline supervisors, management, engineering, and DOE oversight are generally present in the area outside the containment tent to provide direction and support as the disassembly tasks are undertaken. Non-essential personnel are restricted from the area not only to eliminate unnecessary worker exposure, but also to ensure compliance with DOE nuclear materials safeguards and security requirements (Nuclear Material Control and Accountability 2005).

Considering the large degree of work force interaction, it is important to carefully plan each task and limit personnel to only those needed to perform the work. This not only reduces confusion or distraction for those actively completing tasks, but also limits exposure to only essential workers. An operating procedure was developed for the dismantling phase of the Sodium Debris Bed Material Treatment Project to identify not only the steps required to safely and efficiently complete the task, but also the personnel necessary to perform or support each 
step in the process. In order to ensure that workers understand the tasks to be performed, procedural hold points, interactions with supporting personnel, and the hazards and controls for the various elements of the activity, project management also requires a pre-job brief to be conducted prior to performing any work. The pre-job brief is commonly held in a reverse-brief fashion, during which the workers step through the procedure and brief the others on the various steps, hazards, controls, and response to emergency or upset conditions, rather than having a supervisor conduct the brief. Support personnel including radiological controls, industrial hygiene, industrial safety, and environmental provide additional information on elements of the activities that pose special hazards related to their specific discipline. This information will cover requirements for the Radiation Work Permit, the Hot Work Permit, special industrial hygiene or safety considerations including what to look for and how to respond to anticipated hazards, and special waste management handling or packaging requirements. Once all staff supporting the job has been briefed and afforded an opportunity to ask questions related to the tasks being performed, work can begin. At the end of the shift, the workers may also participate in a post-job brief to address unanticipated conditions, difficulties, and additional needs. An important element of the post-job brief is to also discuss those parts of the job that went well. Following the post-job brief, changes to the existing operating procedure may be identified and incorporated before further dismantling tasks are conducted.

\section{Physical Hazards and Controls}

Many physical hazards are present during the SNL experimental assembly dismantling activities. The physical hazards identified and controls implemented are discussed below. These hazards are presented generally in the order in which they are encountered as the dismantling 
phase is carried out, understanding that certain physical hazards are present during several of the tasks associated with this phase of the project.

\subsection{Material Handling and Pinching/Crushing Hazards}

The dismantling phase of this project requires the SNL experimental assembly shipping cask within the PSU to be transferred from the temporary storage location to the dismantling area, and the recovered PCV in its ISC and PSU to be returned to a temporary storage area. The weights of the shipping canisters within the PSUs are expected to range from 400 to 1,500 pounds. The sheer weight of the assemblies presents its own hazard to workers who are required to move them. The design of the PSUs prevents the shipping canister or ISC from tipping over; eliminating a potential crush hazard. Simply moving the storage units, however, could cause musculoskeletal injuries such as strains, sprains, tears, or hernias without controls to prevent overexertion due to the weight of the units. As a result, a variety of mechanical means are utilized to transport the PSUs between facilities. The experimental assemblies or recovered PCVs are primarily move via forklift, however, other means may be used if available space limits or prevents the use of a forklift. The other transfer equipment used to reduce stress to workers includes a pallet jack, Rol-A-Lift pairs, and moving dollies. During the movement of any of the PSUs, at least one worker is used as a spotter to remove obstacles or prevent the load from running into any obstruction.

Other activities that expose workers to potentially heavy loads involve the removal of the shipping canister from the PSU, extraction of the experimental assembly from the shipping canister, and placement of the recovered PCV into the ISC, which is then placed into a PSU prior to being returned to a temporary storage location. In each of these instances hoisting and rigging equipment is utilized to prevent overexertion by workers. The 5-ton facility crane is used to 
remove the shipping canister from the PSU outside the containment tent. Inside the containment tent a secured ratcheting device and tent hoist are used to extract the experimental assembly from the shipping canister. Rail carts inside and outside the tent are used to easily move the shipping canister into place. Once removed the tent hoist and spreader bar, shown in Figure 15, are used to lift the experimental assembly onto the work table. The same equipment is used to repackage the recovered PCV into the ISC. Back outside the containment tent the facility crane lifts the ISC into the PSU. All of these controls prevent stress on workers' muscle and skeletal systems due to the size and weight of the items being maneuvered throughout the dismantlement process. As with any lift it is critical that personnel are appropriately trained and qualified and that this training is verified prior to beginning work. Training and qualifications are reviewed during the pre-job brief.

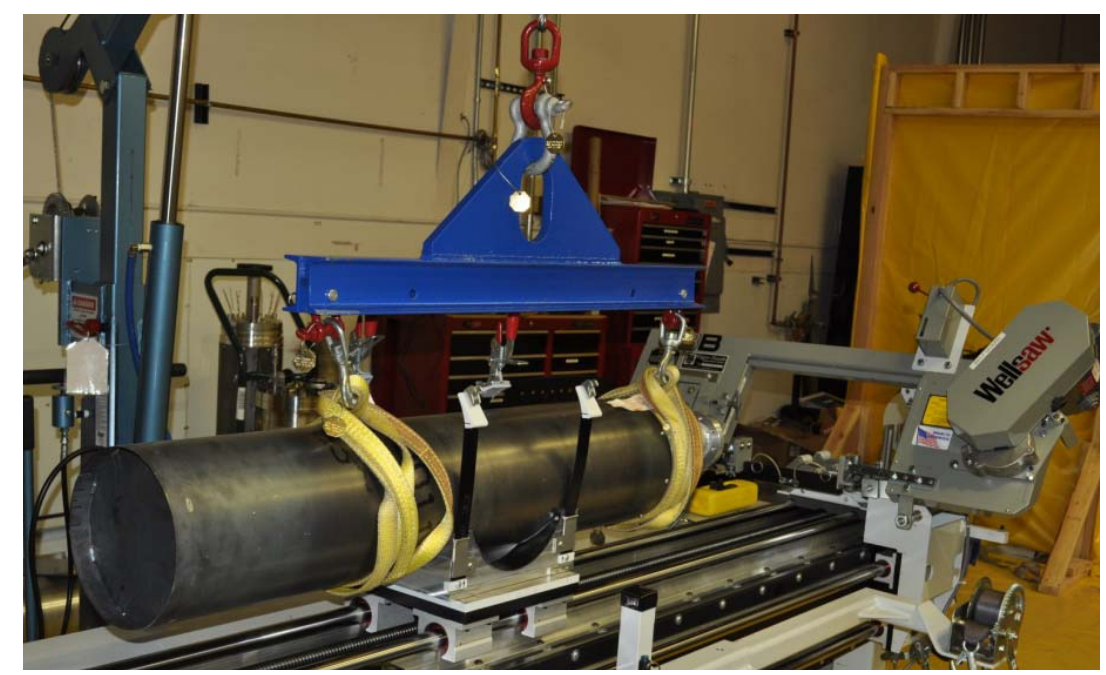

Figure 15. A tent hoist and spreader bar are used to lower the experimental assembly onto the dismantlement work table (Croft, 2013).

In order to remove the experimental assembly from the welded shipping canister, a selfrotating outside-diameter split-frame clamshell tri-tool is used to open the container. This tool presents a pinch hazard to the hands of facility operators performing this task. The pinching hazard is controlled via training to operators on the proper placement and operation of the tri-tool 
cutting device and a mock-up of the cutting activity. Through understanding and practice with the equipment, operators were able to gain needed experience and comfort in its attachment mechanism and operation. Other pinching/crushing hazards associated with dismantlement are mitigated through the use of appropriate PPE including steel-toe shoes and gloves.

\subsection{Radiation}

Workers are exposed to an additional hazard for the first time as the shipping canister is opened. That hazard is radiation and the physical hazards associated with it are two-fold. First, there is the intrinsic hazard associated with the radiation fields emitted from any radioactive material. Since all but one of the experimental assemblies was irradiated to test the performance of sodium-bonded fuel cooling arrangements, the hardware from which the experiment is comprised along with the uranium fuel emits a radiation field. The second hazard associated with the experimental assemblies is the potential for radioactive contamination that either already exists within the assembly due to its construction or that is generated by cutting or otherwise disassembling the experimental unit. Contamination has the ability to be mobilized and spread to other areas if not properly handled. It is therefore more complex to control than radiation fields. Furthermore, radioactive contamination can be introduced into personnel through inhalation, ingestion, or injection. Specific controls to prevent the introduction of contamination into personnel are implemented for this purpose. Chronic exposure to significant levels of radiation is known to cause cancer. As a result, DOE requires any exposure to radiation to be maintained as low as reasonably achievable. The impact of radiation fields on the work force is primarily controlled through the use of reduced exposure time, increased distance, and shielding. Personnel training and mock-ups with the dismantling equipment familiarize workers with the tools and process and result in reducing the time to complete disassembly tasks. Further reduction is 
obtained by grouping the experimental assemblies into families based on similarity in design and construction. As subsequent assemblies within the same family are dismantled, a reduction in the time required to perform dismantling tasks is observed. Distance is utilized during assembly dismantling through the use of rigging for moving assemblies rather than requiring workers to be in close proximity to potential hazards. The use of the self-rotating tri-tool cutter is another example where distance is increased as the shipping canister is opened to reveal the experimental assembly. Shielding is used throughout the dismantling process to reduce worker exposures. The shipping canister and ISC provide shielding for the experimental assembly and the recovered PCV. Shielding in the form of lead or bismuth blankets is also utilized throughout the disassembly process to reduce the radiation field experienced by the workers. Radiation surveys performed at various stages of the dismantlement process monitor the radiation level to which workers are exposed. This monitoring allows for immediate adjustments to be made if unexpected radiation levels are detected.

Radioactive contamination is best controlled by taking preventative actions prior to breaching any system. The most obvious example of this during SNL experimental assembly dismantlement is the use of a containment tent to perform the disassembly tasks. The tent provides a boundary not only for radioactive contamination, but also for other environmental release hazards such as friable asbestos. The use of a sealed sleeve to transfer the shipping canister into the tent and transfer the ISC out of the tent maintains this boundary. HEPA-filtered ventilation provided to the tent is another means to control the spread of contamination beyond the tent boundary. Within the tent contamination is controlled by covering portions of the assembly not being actively disassembled, bagging waste, wearing appropriate PPE, and performing air and radiation monitoring. During the disassembly process the radiological 
controls technician present in the tent smears equipment and assembly edges to determine the presence of radioactive contamination. In addition, bagged waste is smeared both inside and outside the tent by radiation control technicians to ensure there is no spread. Contamination levels that exceed the anticipated levels defined in the Radiation Work Permit result in an immediate stop of work to assess the unexpected condition. The Radiation Work Permit also provides a survey map of the area and required PPE. Working inside the tent requires personnel to don anti-contamination clothing, a powered air-purifying full-face respirator fitted with a P100 particulate removal cartridge, cut-resistant gloves, steel-toe shoes, shoe covers, eye protection composed of safety glasses or goggles depending on the activity performed, and additional dosimetry. The work area is also monitored with handheld radiation monitoring equipment. If unanticipated radiation levels are encountered, personnel are trained to immediately exit the area.

\subsection{Cut Hazards}

The dismantling tasks pose many potential cut hazards, including the equipment used to disassemble the shipping canister and experimental assembly, and the sharp edges associated with the assembly shells during disassembly. The shipping canister is opened with the use of a self-rotating outside-diameter split-frame clamshell tri-tool. The cutting hazard was mitigated through selection of the tool used. By choosing a self-rotating cutter the operator is not in close proximity during the cutting operation. Other cutting equipment is provided on the dismantling horizontal work table. This table is equipped with a band saw for making either circumferential or through-cuts on the experimental assembly. The table is also equipped with an electric slitting jointer mounted to a rail system on the table for making longitudinal cuts. Both of these tools are equipped with guards to prevent inadvertent cuts to workers in the vicinity. The guard for the band saw is removed as directed by the operating procedure just prior to making a cut and 
replaced immediately following each cut. The jointer is equipped with a permanent guard to prevent hands or fingers from entering the cut path. The operating procedure also requires the power to all motorized equipment to be removed when not in use to eliminate inadvertent cuts. Power is provided to each tool just prior to its use and removed immediately afterward. Additional controls implemented to reduce the likelihood of cut injuries to personnel are associated with the work table's assembly and disassembly equipment securing features. Once placed onto the work table the assembly is secured using straps to a saddle mounted to the carriage the runs along the table. The end of the assembly is also attached to a pipe bully when cuts are made to further prevent unintentional movement of the assembly during cutting tasks. The band saw is attached to the table, providing a secure base that prevents movement. A feature added to the saw after operations were started is the addition of a depth gauge that can be used in conjunction with the rotating pipe bully to complete precise circumferential cuts. This allows the worker to complete these cuts without placing their hands near the cutting area. Longitudinal cuts are made with the slitting jointer. As described, the jointer is attached to horizontal rails on the table that allow easy movement without placing hands near the cutting area. The table also contains a variety of spacers, shims, and jacks that are used to secure the ends of the assembly and prevent shifting during any of the dismantling activities. The cutting equipment provided on the work table is illustrated in Figure 16. 


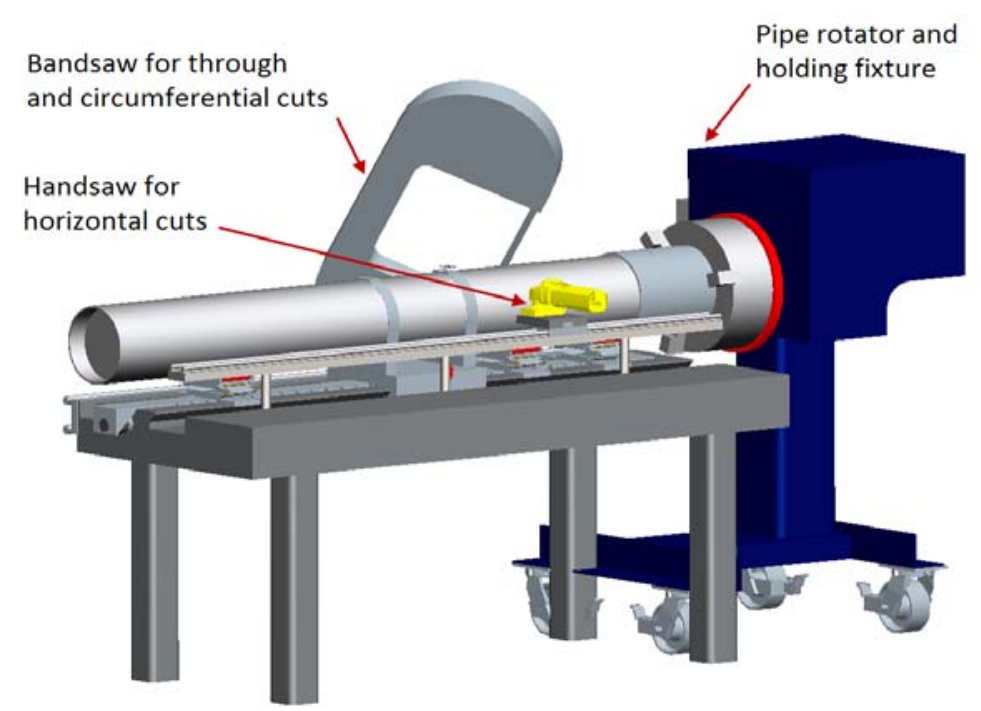

Figure 16. Illustration of the containment tent work table with band saw, slitting jointer, and pipe holding and rotating fixture (Conceptual Design Report for Sandia Sodium Debris Bed Material Treatment, 2011).

Another significant cut hazard associated with dismantlement is the sharp metal edges associated with the cut shell ends and instrument tubing of the assembly. In order to prevent workers from experiencing cuts due to unintentional contact, the edges are wrapped with foam and/or tape after each cut as directed by the operating procedure. Wrapping sharp edges is a common step in cutting work at the INL also due to the concern about the injection of radioactive contamination into an open wound. A major concern during disassembly of the SNL experimental assemblies is the presence of multiple, nested metal layers within the unit. It is important that operators recognize and cover all the metal layer edges present within the structure prior to performing subsequent disassembly steps. It is also important to ensure that an adequate amount of foam or tape is applied to the edge to prevent sharp areas from cutting right through the padding. The use of two operators and cut-resistant gloves to perform disassembly in the containment tent provides an appropriate amount of assistance when applying padding to sharp edges to avoid cuts while the padding is attached. The padding prevents cuts during subsequent disassembly steps such as sliding metal shells off the experimental assembly. 


\subsection{Fire Hazards}

The disassembly work conducted in the containment tent poses a fire risk to any combustibles within the tent and the tent itself. The primary sources of heat in the tent are related to either hot equipment or hot pieces of metal resulting from the cutting operations performed. As dictated by the operating procedure, a metal catch pan is placed below the experimental assembly whenever cutting operations are performed. This is designed to collect any hot metal that could be released while cuts are made with the band saw or slitting jointer. After any cut is made the immediate area is also inspected to verify that any loose metal pieces have fallen into the collection tray.

A Hot Work Permit was also generated for the disassembly activities performed in the dismantlement area containment tent. The Hot Work Permit identifies the special precautions required for cutting including the use of the metal catch pan and observation by the other operator in the containment tent during active cutting. The permit also identifies combustible loading limits for the tent. The amount of combustibles associated with the dismantling phase of the project is very low so the presence of combustibles is not a major concern. Despite this, a fire watch is required by an independent party during cutting activities in the containment tent. Materials removed from the assembly during dismantlement are immediately bagged and removed from the containment tent to a waste box to prevent a buildup of materials. Finally, the Hot Work Permit contains special cautions and instructions for responding to a fire within the tent. Special attention is given to the presence of sodium in the experimental assemblies. Although the assemblies were constructed with the sodium fully contained within the interior PCV, it was assumed for dismantlement planning that the primary containment could be breached, potentially allowing metallic sodium to escape. A metal fire is classified as a Class D 
fire and must be extinguished with a special material such as Metal $\mathrm{X}$ foam. The fire is extinguished by removing oxygen and smothering the fire. A Metal $\mathrm{X}$ fire extinguisher is contained within the tent. Class A,B,C fire extinguishers are also appropriately staged in the area. The dismantlement facility does not contain a fire sprinkler system due to unrelated criticality concerns. This facility feature reduces the concern of a water/sodium reaction in the event that the PCV is breached.

\subsection{Slips and Trips}

Slips and trips are of primary concern during dismantlement activities due to the small area within the containment tent, the use of a variety of tools, the presence of electrical cords to run equipment, and the soft, smooth tent floor surface. Some of this concern was avoided by including a tool chest within the containment tent. This provides a location to store hand tools, which keeps them from being placed on the floor and creating a tripping hazard. Electrical cords are also routed through the tent in areas that are not typically occupied during the disassembly activities so that they would not pose a tripping hazard. The tent floor was secured by a metal frame and held in place within the tent by the work table, tool chest, transfer cart, and other heavy equipment. Prior to performing work the tent is inspected to verify there are no tripping hazards, such as tools or wrinkles in the floor. The operating procedure also requires routine cleaning of the tent floor with a HEPA-filtered vacuum during some disassembly activities to ensure any material is quickly removed. Slips are controlled by preventing the use of liquids within the tent.

\subsection{Ergonomics}

The areas of greatest ergonomic concern are related to material handling, containment tent work table and associated equipment height, and the use of a variety of hand tools. Material 
handling has already been discussed. The containment tent work table and preferred tools for use were reviewed by INL industrial hygiene and safety professionals prior to selection and use. The height of the work table and connected equipment was established to accommodate the height of the operators performing work within the tent. The height of the facility operators do not vary appreciably, however, to accommodate a variety of worker statures the table was equipped with jacking tubes that allow the height to be adjusted. Due to concern that the removal of nested layers within the experimental assemblies would result in awkward body positions, the work table is equipped with a power-assisted sliding table-top. In this way the operators are able to secure one end of the assembly to the table or hold the end with hand tools while the table carriage assists in sliding the nested layer off.

Related to the disassembly process, the use of hand tools generally occurs for only short periods of time. There is therefore no significant concern about the development of repetitive use or stress-related injuries to the hands, arms, or shoulders. Force is a consideration during the disassembly activities so hand tools of various sizes are provided, larger tools that provide greater force and smaller tools for more precise work where less force is required. Large cutting tools have been attached to the table and horizontal rails provided for ease of use. Pliers and other hand tools have been selected with soft edges so as not to exert undue pressure on the hands during use. To relieve stress on the feet and legs during extended activities, ergonomic mats may be provided as needed.

\subsection{Electrical Hazard}

The use of powered equipment, combined with the motorized cutting equipment, provides an opportunity for electrical shock. The potential to cut electrical cords was eliminated by securing power cords in areas that are far-removed from cutting equipment. The possibility of 
electrical shock or inadvertently starting power equipment is controlled through the operating procedure, which requires that electrical equipment remains unplugged when not in use and while performing any maintenance activities. Power is restored just prior to using the equipment and immediately disconnected following its use. All operations personnel performing work with powered tools are also required to complete Electrical Energy Awareness Training. All training is verified during the daily pre-job brief.

\subsection{Pressurized Systems}

Following the repackaging of the recovered experimental assembly PCV into the ISC, the atmosphere within the storage container is purged and filled with inert argon to ensure the contained sodium will not react with air in case of a breach of the PCV. The argon is supplied by a separate, compressed gas cylinder. Using compressed gases can result in personal injuries if tubing systems are not connected properly or malfunction. This could cause tubing and connections to come loose and be propelled by the escaping gas, resulting in strike against injuries if the worker is in close proximity. This condition is controlled via compressed gas cylinder training and the use of PPE. Personnel providing connections to any compressed gas cylinder are required to complete training prior to performing work. In addition, individuals working with the argon compressed gas cylinder are required to don steel-toe boots, gloves, and safety glasses.

\section{Chemical Hazards and Controls}

In addition to the physical hazards encountered while performing experimental assembly dismantlement, the assemblies themselves present a variety of chemical hazards as well. These are discussed in detail in the following sections. As with the physical hazards, the chemical hazards are generally presented in the order in which they would be encountered. 


\subsection{Heavy metals}

The dismantlement process requires cutting through several metal components. These components are comprised of metal alloys that contain some heavy metals, to which workers may be exposed during cutting or other disassembly activities. The stainless-steel shipping canister is cut open in order to extract the experimental assembly. Once removed, the stainlesssteel or Inconel metal shells must be unbolted or cut in order to remove them. Stainless-steel is an alloy that generally contains $18-20 \%$ chromium and 8-12\% nickel (Engineers Edge). Inconel provides better corrosion resistance than stainless-steel. It can contain from $46-72 \%$ nickel, $15-23 \%$ chromium, and may also contain molybdenum (Niko Steel Industries). When either of these alloys is cut workers may be exposed to these heavy metals primarily through inhalation. The health effects associated with overexposure to chromium depend on the oxidation state of the chromium. The effects of chromium exposure via inhalation can include skin rash, ulceration of nasal mucous membranes, irritation of the pharynx and larynx, asthmatic bronchitis, bronchospasms, edema, shortness of breath, gastrointestinal upset, ulcers, kidney and/or liver damage, and possibly lung cancer (Science Lab, Chromium, 2013). Possible health effects that could be encountered as a result of overexposure to nickel include: irritation or sensitization of the skin; eye irritation; respiratory tract distress with non-productive cough, hoarseness or sore throat; headache; chest discomfort; vertigo; pulmonary edema; and pulmonary fibrosis. Metallic nickel is generally considered not to be acutely toxic when ingested (Science Lab, Nickel, 2013). Inhalation of molybdenum could result in irritation to the upper respiratory system, anemia, pneumoconiosis, hyperthyroidism, abnormal liver function, and an increased susceptibility to gout. Exposure could also cause contact dermatitis and irritation of the eyes (Molybdenum.com). It is important to note that from a waste management perspective that chromium and nickel in 
adequate quantities may also be considered hazardous waste requiring specific characterization and disposal requirements (Government Printing Office, 2014).

Personnel supporting the dismantling effort are protected against exposure to the heavy metals contained in the experimental assembly metallic structures by the cutting equipment selected and PPE worn. All of the workers inside the containment tent, typically comprised of two facility operators and a radiological controls technician, don protective outer garments in the form of anti-contamination clothing, gloves, eye protection, and a powered air-purifying full-face respirator fitted with a P100 particulate cartridge. The cartridge selected for the respirator is adequate to remove metal dust as well as radioactive contamination and asbestos. Personnel are required to complete INL Respirator Training prior to being issued a respirator and must refresh that training every other year. In addition, all respirator-qualified personnel must undergo medical evaluation to verify adequate lung capacity and receive quantitative fit testing for the respirator issued. The containment tent possesses an adequate oxygen environment to perform disassembly with the use of air purifying respirators, as opposed to an air supplying system. Adequate containment tent ventilation flow is verified each day prior to initiating work.

\subsection{Asbestos}

As previously identified, five of the eleven SNL experimental assemblies contain asbestos in the thermal insulation layers. Asbestos is a naturally-occurring mineral fiber found in rock and soil. Due to its heat resistance and natural fiber strength, asbestos was used for many years as a construction material in insulation and as a coating for a variety of materials to provide fire resistance. The mineral composition of asbestos makes it a resilient material for construction. Unfortunately, these same characteristics, combined with the small diameter of the typical asbestos fiber, cause it to be equally resilient in the human body. 
Once taken into the body, typically through the inhalation exposure pathway, asbestos fibers that are deposited and not removed via phagocytic cells may be encapsulated in cells within the lung. The fibers cannot be broken down or easily removed by the body. As a result the fibers tend to remain largely transient where they first become embedded in the lungs. The initial effects of exposure to asbestos are usually transparent. Over time, however, exposure to asbestos increases the likelihood of developing lung disease. The three major health conditions arising from asbestos exposure are:

- Lung cancer

- Mesothelioma - a specific type of cancer that originates in the thin lining of the lung and can quickly spread to the chest, abdomen, and heart

- Asbestosis - a progressive, non-cancerous form of fibrosis in the lungs (United States Environmental Protection Agency, 2015).

As these potential health effects were recognized, the United States Environmental Protection Agency banned asbestos from a variety of uses throughout the 1970s.

The workers inside the containment tent are protected against asbestos exposure in a number of ways. First, the disassembly process detailed in the operating procedure utilizes a glove bag for those experimental units that contain asbestos insulation. During construction of these assemblies, the outer shell was bolted on, rather than welded, which should allow for disassembly with minimum disruption of the asbestos insulation. Prior to beginning the disassembly process, a plastic sheet is laid on the work table below the assembly to prevent contamination of the table. Next, a glove bag is installed over the end of the assembly. The fastening bolts are removed within the glove bag and the assembly is slowly dismantled. The glove bag is designed such that it is slightly longer than the length of the experimental assembly. 
As the shell is removed, the glove bag expands to contain the entire shell piece removed. The shell is removed slowly so that the insulation layer associated with it can be removed with it. Once both the shell and insulation are removed from the assembly, masslin wipes are used within the glove bag along the entire length to clean the area to the extent possible. The contents are all sealed into the glove bag and removed. During the cleaning process, the nozzle of a HEPAfiltered vacuum is inserted into the glove bag to collect friable asbestos fibers that may be liberated during the process. After the glove bag is sealed and the waste containing portion removed, the plastic sheeting on the table is removed and the entire area cleaned with masslin wipes and the HEPA-filtered vacuum. All asbestos-containing material is then placed into a second bag prior to removal from the containment tent as waste (Technical Safety Requirements Procedure, 2015).

The order for processing the experimental assemblies is another control for reducing the potential of asbestos exposure. Those assemblies containing asbestos insulation are intentionally processed last. In this way the potential duration of asbestos exposure to workers in the tent is reduced as compared to a situation where the asbestos-containing assemblies are dismantled earlier in the process. All workers in the containment tent are also required to complete asbestos training prior to performing work. The information provided in this training helps workers to be more proficient in handling asbestos-containing materials without releasing asbestos fibers to the work area. Training is verified during the pre-job brief. Finally, asbestos monitoring is also conducted within the containment tent so that data can be obtained regarding the actual level of asbestos fibers present. The presence of the containment tent itself provides protection to those outside. 


\subsection{Sodium}

Sodium is an alkali metal that is extremely reactive with water, even to the point that it can burn in moist air with a bright yellow flame. In relatively dry air freshly exposed sodium will quickly form an oxide layer that will impede further reaction with the air if undisturbed. Metallic sodium reacts violently in water producing sodium hydroxide and releasing hydrogen gas. Under conditions where the hydrogen can accumulate, thereby increasing the concentration, a violent explosion ignited by the sodium flame may result. Although the sodium bed was fully contained within the sealed experimental assembly PCV when they were constructed, it is assumed by the dismantling team that the containment may have been breached during irradiation, handling, or testing. While sodium can cause irritation or burns to the skin on contact, it is generally considered non-toxic (Chemicool, 2012). The primary concern for sodium during this activity is to prevent or minimize any highly exothermic reaction, if possible.

Related to the dismantling of SNL experimental assemblies, the best means to reduce the potential for reaction of sodium in the air is to recognize any breach in the primary containment and mitigate any reaction if a breach is discovered. As described above, metallic sodium rapidly forms an oxide layer when exposed to air resulting in a dull gray appearance. Fortunately, much of the work at INL involves sodium and, as a result, facility operators are familiar with its characteristics and appearance. Mock-up testing and operator training provided additional direct experience utilizing surrogate PCVs containing typical kilogram quantities of metallic sodium. The operating procedure for dismantling contains precautions in the event sodium is encountered. The primary response for operators in the event unreacted sodium is detected is to place the assembly in a secure condition and exit the containment tent until the situation can be further evaluated. If oxidized sodium is identified, this may be as simple as backing away and 
noting the condition for further evaluation. If disassembly results in a sodium reaction then the operators may discharge the Metal-X extinguisher, if the amount of sodium involved is small, or exit and notify the INL Fire Department if the reaction is more involved. Ultimately, a breached PCV will be managed in much the same way as the other vessels once the situation is evaluated and appropriate safety precautions are implemented. The vessel will be transferred into a secondary container, which will then be purged and filled with inert argon gas.

\subsection{Uranium}

The source of nuclear fuel contained within the experimental assembly is enriched uranium oxide. Apart from its radioactive characteristics, uranium is also a chemical that can be toxic in high concentrations. Most people ingest very low quantities of uranium in the water they drink as well as fruits and vegetables they consume. In addition, very low concentrations may be inhaled due to the presence of uranium in soil and some rock formations. Although the primary health concern with exposure to uranium is related to the strong gamma rays that are emitted, there is also some evidence that uranium can have chemical health effects on the kidney, although most information regarding the chemical health effects from uranium exposure are based on animal studies (Agency for Toxic Substances and Disease Registry, 2009).

Chemical exposure to uranium during the dismantlement process is considered highly unlikely due to its location within the experimental assembly. Like sodium, the uranium fuel is

contained within the PCV of the assembly. Unlike sodium, however, a breach of the PCV would not expose workers to the chemical characteristics of uranium. This is because the uranium is covered by a bed of sodium that would prevent direct contact with the uranium even if the primary containment were breached. If workers were exposed to uranium contamination, the PPE required due to the other hazards associated with the assemblies would be sufficient to 
prevent chemical exposure. Of course, exposure to the radiation field associated with the uranium would be a significant concern and likely cause the workers to apply temporary shielding and exit the containment tent until a recovery plan for the condition is prepared and approved.

\subsection{Asphyxiants}

The use of argon to provide an inert atmosphere around the recovered PCV in the ISC poses a potential asphyxiant hazard. This hazard is largely controlled by the small size of argon cylinders used. All workers associated with the use of the argon cylinders are also required to complete compressed gas cylinder training, which addresses asphyxiant hazards. All training is verified in the daily pre-job brief.

\section{Mock-up and Readiness Assessments}

In order to shakedown the facilities, documentation, and staff prior to beginning radioactive operations, a series of mock-ups and readiness assessments were completed. A description of these activities and some of the changes made to the process as a result are described in the sections below.

\subsection{Dismantlement Mock-up}

Prior to initiating the dismantling phase of the INL Sodium Debris Bed Material Treatment Project, mock-ups of the critical activities using the actual dismantling equipment along with surrogate shipping canisters and experimental assemblies were performed. The purpose of the mock-ups was to verify the equipment identified and developed to complete the activity was adequate to perform the tasks as designed. Performing the mock-up tasks also allowed industrial hygiene personnel to gauge how the disassembly tools and equipment met the physical stature, force, and reach needs of the facility operators who would be using them. One 
final goal of the mock-up testing was to allow dismantling personnel to qualify and gain proficiency with the actual equipment that would be used on the experimental assemblies resulting in reduced time to disassemble the irradiated material and lower exposure to the workers involved.

So as not to disturb facility modifications that were ongoing at the dismantlement location, the dismantlement operations were initially mocked up at a separate location with additional trial evolutions occurring at the dismantlement facility later. Five full surrogate experimental assemblies as well as shipping canisters were fabricated so that the complete dismantlement process could be performed. This portion of the testing included an evaluation of the transfer cart and its interface with the containment tent and work table, attachment and use of the tri-tool cutter, location and use of the work table assembly securing mechanisms and cutting equipment, and evaluation of the PCV repackaging including tests specific to the loading equipment. Separate mock-ups included an electrical pass-through cylinder to demonstrate cutting through wires and tubing within an assembly, and a pull-test mock up for testing and adjusting, as necessary, the pulling force of the work table linear rail system (Mock-up Test Plan, 2012).

Based on experience gained through the mock-up effort, various adjustments were made to dismantling equipment and corresponding operating procedure steps. One such change is that the process speed of the tri-tool cutter was adjusted to improve the cutting efficiency when opening the shipping canister. Similar adjustments were made to the band saw speed and the slitting jointer to keep the tools stable when cutting the surrogate experimental assemblies. One specific procedure change that was made as a result of mock up operations was related to some of the tubing running through certain assemblies. It was determined that some tubes or rods 
which had been screwed into place via threads on the end of the tubes in some assemblies would unscrew rather than be cut when engaged by the band saw. When this occurred the unscrewed tubes simply moved toward the bottom of the assembly and began to roll causing the saw to bounce. The operating procedure was changed so that the entire assembly is rotated 180 degrees prior to cutting so that the tubes would tighten and the uncut area could be severed. Another refinement made as a result of mock-up testing is that the ISCs were fitted with baskets for safely lowering the PCVs into them. These baskets help to stabilize the load as the PCV is lowered inside. Finally, the mock-ups allowed procedural run-throughs that allowed the steps to be refined based on mock-up lessons learned.

\subsection{Readiness Assessments}

Two formal readiness assessments were completed prior to starting radioactive operations to demonstrate that the facilities, equipment, staff, and procedures were ready to initiate the dismantling phase of the project. The first assessment, performed in October 2013, was a management self-assessment. The management self-assessment included staff assigned to the dismantlement project and was performed to demonstrate readiness to the project management team. The self-assessment focused on the following key areas:

- Training and qualifications

- Management and staff level of knowledge related to the tasks to be performed

- DOE-required facility safety documentation

- Status of facility modifications

- Workable procedures are in place

- Demonstration of disciplined operations (Management Self-Assessment, 2013). 
The management self-assessment was completed over several weeks and involved document reviews, interviews with operations and support staff, and demonstration of work activities within the dismantling containment tent. The assessment team identified 15 pre-start findings and zero post-start findings. Several opportunities for improvement were also identified, as well as a few noteworthy practices. The dismantlement staff quickly went to work to categorize findings, identify responsible staff members to lead efforts on each finding, and begin to close out each item. Once all pre-start findings had been addressed to the satisfaction of project management and the assessment team a second assessment, termed a contractor readiness assessment was initiated. This assessment was completed in March, 2014 by members of the same contracting company, but who were independent of the INL Sodium Debris Bed Material Treatment Project.

The contractor readiness assessment focused on five project elements considered to be core requirements. These were:

- Affected personnel have been adequately trained

- DOE-required safety basis documentation is approved and implemented

- Conduct of engineering has been followed and incorporated into the project

- Accurate and adequate procedures are approved and issued

- Conduct of operations is established and maintained in the facility.

Readiness assessment team members were assigned to each of these core areas. The assessment included reviews of program description documents, procedures, nuclear safety requirements, training courses and completion records, and worker qualifications. The team also conducted interviews of project management, engineering, safety and health, operations, maintenance, radiological controls, and quality assurance staff. Finally, the assessment team 
observed a mock dismantlement evolution with team members assigned to focus on specific elements or disciplines (Contractor Readiness Assessment, 2014). The 15 pre-start findings from the management self-assessment conducted the previous year and actions taken to close them were independently reviewed and found to be satisfactorily addressed.

At the end of the readiness assessment the team identified six additional pre-start findings and one post-start finding. Findings from the two assessments included: ensuring stability of the transfer cart inside the containment tent; control of items being cut from the shipping canister; requiring the use of hard hats when working in proximity to the facility crane hook; inaccurate reading on the pressure gauge associated with the ISC after a purge and fill operation; ratchet straps for the work table were connected improperly; better documentation of HEPA filter testing and adequate containment tent ventilation (4 air changes/hour); using gloved hands rather than a tool to remove captured metal chips and shavings from the catch pan in the containment tent; an awkward employee position used to reach to tent hoist hook; improving documentation demonstrating completion of qualification training; and recording the final as-built condition of facility modifications. The assessment findings led to several changes to the operating procedure and other support documents, as well as verification of personnel training and qualifications. Facility staff provided formal closure paperwork for each finding to the assessment teams for evaluation and concurrence prior to closing any item. During the summer months of 2014, the project team declared readiness to begin actual operations.

\section{Dismantlement Operations}

The dismantlement phase of the INL Sodium Debris Bed Material Treatment Project began in late 2014 with the transfer of the first PSU to the dismantling facility. In accordance with the processing order developed during the dismantlement trade study sessions, the first 
experimental assembly to be dismantled was the one assembly that had not been irradiated. This assembly was selected as the first to be processed due to the absence of radiation as well as its very simple design as compared to the remaining assemblies. This particular assembly was comprised of simply a PCV placed into a welded shipping canister. This simplest arrangement offered an excellent opportunity for the dismantlement staff to complete the entire operation and test the procedural and equipment modifications made as a result of the preceding mock-up testing and readiness assessments in a relatively low-risk environment. The hoisting and rigging process to remove the shipping canister from the portable shipping unit and place the canister onto the transfer cart went smoothly, as did the transfer operation into the containment tent. Once the shipping canister was opened with the tri-tool cutter, the PCV was removed and repackaged directly into an ISC. The container was transferred back out of the containment tent, purged and filled with argon, and placed into a PSU without any issues. Finally, the PSU was relocated back to a temporary storage location, successfully completing the first of the eleven assemblies. No equipment or procedural modifications were made as a result of this first dismantling iteration.

Since that time six additional experimental assemblies have passed through the dismantlement process. As the processing order dictates, the assemblies were assigned to families based upon the mode of construction, the complexity associated with the disassembly process, and the level of hazard anticipated. Although the processing of these additional assemblies went relatively smoothly there were at least two unanticipated conditions that required a temporary stoppage of work to address. While disassembling some of the experimental assemblies a metallic powder was identified between some of the nested shells. When discovered, the assembly was placed in a secure condition and the containment tent exited to evaluate the unexpected condition. While the drawings of the assemblies did not indicate the 
presence of any such material, a report on the sodium debris bed units was found that referenced the use of copper powder in certain assemblies to improve heat transfer characteristics between the shells. The heat experienced by the assemblies was high enough in some locations to begin to sinter the copper granules, which resulted in difficulties separating the shells. Since the initial operating procedural steps indicated the shell layers could be manually pulled apart, the procedure had to be changed to require cutting of a series of shell layers in much smaller sections and removing them and the underlying copper material together. The procedure was modified and work authorized to proceed. Using the revised procedural steps, the operators were able to successfully remove the nested layers down to the PCV without further incident. In another experimental assembly, a deeper weld penetration than expected was encountered. Similar to the copper powder, this cause nested layers to stick together. In this case the assembly was cut further along the weld to release the metal shell pieces.

The most recent experimental assembly processed was the first of five that contain asbestos insulation. The additional equipment and supplies necessary to process these assemblies, including the HEPA-filtered vacuum, glove bags, and plastic sheeting material were staged prior to beginning this stage of the effort. The experimental assemblies containing asbestos insulation have been subcategorized into two families based on their construction and complexity. As with the previous processed assemblies, those with the simplest construction and having the lowest radioactivity will be dismantled first. This allows the dismantlement staff to gain proficiency as consecutive assemblies are processed, speeding the disassembly time and thus reducing worker exposures to radiation and asbestos. The final assembly to be dismantled experienced an unexpected pressure loss during experimentation at SNL. Since it is not known whether this is due to simple instrument failure or a breach of PCV, it will be opened last with 
greater preparation given to the potential for sodium release. The first asbestos-containing assembly dismantlement went smoothly. The asbestos insulation did not appear damaged and slid smoothly the entire length of the assembly with no visibly friable releases. The glove bag worked as anticipated and the disassembly took no longer than for those not containing asbestos.

\section{Lessons Learned}

Through the use of dismantling mock-ups, readiness assessments that included surrogate process evolutions, and actual disassembly and recovery of the PCV for six of the eleven experimental assemblies, several lessons have already been learned. These lessons have resulted in a variety of adjustments to paper, process, and people. Other lessons learned were positive in nature, reinforcing certain actions taken in the planning or preparation processes. While some of these have been touched upon in other sections, all lessons learned and adjustments, if any, associated with the dismantlement phase of the project that has been completed to date, are summarized below.

- Recording the final condition of facility modifications - The analysis of the false floor constructed to cover the pit and trench in the selected dismantlement facility did not include final as-built drawings illustrating the modification. The appropriate drawings were added and the analysis evaluated to ensure the floor loading conclusions remained valid.

- Potential for the transfer cart inside the containment tent to become unstable if the assembly is not centered on the cart when loaded - The operating procedure was revised to require that the assembly is centered on the cart when extracting it from the shipping canister. The operators are required to check the position of the 
assembly after it is extracted to ensure it is centered on the cart before proceeding to the next step.

- Control of items being cut from the shipping canister - It was found during the mock-up testing that the end of the shipping canister could twist during the cutting operation. No changes to the procedure or process were made since personnel are not in close proximity to the tri-tool cutter during its operation. No risk to personnel or equipment is anticipated.

- Additional PPE required when working in proximity to the facility crane hookDuring one of the mock-up exercises, while a worker was reaching for the facility crane hook to attach it to the shipping canister, an observer noted the potential for a worker to be hit in the head by the hook during such an activity. The PPE for the task was revised to include a hard hat while working with overhead equipment.

- Inaccurate reading on a pressure gauge during purge and fill operation - During a mock-up of the repackaging operation, an operator noted that the pressure gauge on the ISC indicated a slight negative pressure after a purge and fill activity. The pressure gauge should have indicated positive pressure following the fill step. The equipment was checked and the gauge replaced. Subsequent purge and fill evolutions resulted in expected pressure readings.

- Ratchet straps on the dismantling work table connected improperly - During one readiness assessment evolution it was determined that the ratchet straps holding the work table tilting fixture during PCV repackaging did not have the end hooks connected to each other. The operating procedure was revised to require operators 
to verify ratchets straps are connected appropriately before proceeding. This was also mentioned during subsequent pre-job briefs.

- Documentation of HEPA filter checks and containment tent ventilation requirements - Although documents related to the dismantling operation indicated that daily checks of HEPA filter differential pressure would be performed and adequate containment tent ventilation ( 4 air changes/hour) would be maintained, it was unclear how these conditions were verified in the field. Upon investigation it was found that HEPA filter checks were documented on daily inspection forms. Proper containment tent ventilation flow was verified with a flow meter to ensure at least 4 air changes/hour would occur.

- Revising the work practice to remove captured metal chips from the containment tent catch pan - During a readiness assessment work evolution a worker was observed emptying metal chips from the catch pan below the band saw with gloved hands. This was determined to be an inadequate level of protection to prevent lacerations to the hand. A metal tool was identified for scraping the metal shavings from the catch pan and facility operators were informed of the change during subsequent pre-job briefs.

- Awkward employee position to retrieve the containment tent hoist hook - During a readiness assessment mock work evolution a facility operator reached in an awkward position well above the head to catch the swinging tent hoist hook while trying to remove the spreader bar. Personnel were coached on maintaining proper body position during such activities by lowering the hoist hook to a greater extent 
and stabilizing the spreader bar to stop swinging prior to detaching it. This behavior was reinforced during pre-job briefs.

- Unclear documentation demonstrating completion of qualification training for certain workers - The Qualified Watchstanders List, identifying personnel who would perform the fire watch identified in the Hot Work Permit, did not contain adequate information to allow first line supervisors to verify personnel had the appropriate qualifications. The list was updated to include appropriate qualification information for the personnel identified.

- Addition of band saw depth gauge - During initial dismantlement operations it was determined that greater control over the depth of circumferential cuts was desired. A depth gauge/adjustable stop feature was added to the band saw to allow for precise circumferential cuts when used in conjunction with the rotating pipe bully allowing better control when separating nested layers within the experimental assembly.

- Participation of impacted disciplines during early planning and trade studies Including all affected parties throughout the planning process helped to identify potential obstacles early on and focus project efforts to maximize the ability to succeed. The process of providing several alternatives and then reaching agreement on the best path forward with the input of all disciplines responsible for the success of the effort eliminated distraction and unified support as the project was carried out.

- Full-scale mock-ups - When staff was interviewed regarding lessons learned during dismantling activities, one of the most popular answers dealt with the use 
of realistic mock-ups to test the facilities, procedures, and employees.

Adjustments were made throughout the process as a result of these mock-ups. The construction of realistic experimental assemblies prepared workers and provided them an opportunity to perfect methods and experiment with alternate approaches. Repetition of tasks with the actual equipment that was used on the assemblies also provided workers with valuable experience that reduced radioactive stay times during "hot" operations.

- Multiple readiness assessments - Separate assessments, first primarily by dismantling personnel and then by an independent contractor team, verified that all elements considered necessary for successful operations had been carried out. The first assessment team identified several pre-start findings that had to be closed prior to conducting the second assessment. The contractor readiness assessment team reviewed findings from the management self-assessment as part of their review to verify that the findings had been closed appropriately. By the conclusion of the two assessments a high level of confidence had been instilled not only in dismantlement staff, but also in DOE oversight personnel.

- Verification to close out assessment findings - In order to close out findings from either of the dismantling phase readiness assessments, formal documentation of actions taken and objective evidence that the actions had been completed had to be provided to a member of the assessment team. Once verified and signed off by a team member, the finding could be closed. Although this process is a bit laborintensive it ensures effective actions have been taken by providing a means of independent review and validation. 
- Processing order - As described previously, the SNL experimental assemblies were processed in an order taking into account unit complexity, similarity in construction, anticipated radiation dose, and the presence of asbestos. The least complex assemblies with the lowest dose were processed first. Similarly constructed assemblies were grouped into families and further ordered by complexity and radiation dose. Asbestos-containing assemblies and one that is considered more likely to have a breached PCV are performed last. This identified order allowed for active learning by workers that improved their performance on subsequent assemblies and reduced exposure times.

- Pre-job and post-job briefs - Conducting consistent briefing sessions verifies understanding of the process, hazards, controls, and emergency response actions by all workers involved in the process. Pre-job briefs also provide an opportunity for workers to ask questions prior to beginning work each day. Reverse-briefing is considered the preferred means of completing a pre-job brief since those performing the work conduct the briefing. Post-job briefs provide workers with an opportunity to discuss what went well in addition to opportunities for improvement. Performing post-job briefs consistently, each day that dismantling activities are conducted is considered a best management practice.

\section{Conclusion}

The INL was tasked with recovering reusable nuclear material from eleven experimental sodium debris bed fuel assemblies constructed at SNL from the mid-1970s through the mid1980s. Due to delays in design and fabrication of equipment to separate the metallic sodium from the uranium oxide fuel, the project was divided into two phases. The first phase, referred to as 
the dismantlement phase, includes transfer of the experimental assembly from temporary storage to the dismantlement facility, disassembly of the unit, recovery of the internal PCV which holds the nuclear fuel within an integral sodium bed, and repackaging and transfer to temporary storage of the recovered PCV. The second phase, called the recovery and disposition phase, entails the use of thermal vacuum distillation to separate the sodium from the uranium, recovery of the nuclear fuel, transfer of the recovered material to the appropriate facilities for reuse, and treatment or disposal of any wastes.

Planning for the dismantlement phase of this project involved a series of trade studies comprised of representatives from all INL organizations impacted by dismantlement activities. The experimental assemblies are generally comprised of nested layers of stainless-steel intermixed with layers of thermal insulation and a variety of instruments. The goal of the dismantlement phase is to unfasten or cut the steel layers, one-at-a-time, and slowly peel the layers away. A work table with integrated cutting tools, and a variety of hand tools, were provided to complete disassembly. Trade study participants selected a preferred location to perform the disassembly functions based largely on available space, competing projects, and costs associated with facility modifications. The trade studies also identified the preferred means of providing containment to protect workers from the hazards associated with these experimental assemblies, most particularly radiation and asbestos. Trade studies also led to the selection of the means by which disassembly of the assemblies would occur with the use of a work table, hand tools, manual power tools, and fixed mounted power tools that can produce radial, longitudinal, and through-cuts of the assembly.

At the same time that the trade study team was assembled and discussions commenced, a separate team developed a document identifying all the functional and operating requirements 
applicable to the full scope of the dismantling effort. This document included all applicable federal and state regulations, DOE directives, professional and trade organization standards, and internal company programs and procedures. Identification of applicable requirements allowed planning and design to proceed in an organized and controlled manner.

Because the dismantling activity requires coordination between several disciplines but occurs in a relatively small containment tent, one of the greatest staffing considerations was to determine the type and number of employees that would actively work in the tent and how interaction with the other disciplines would occur. It was ultimately decided that two operators and one radiological controls technician would perform work inside the tent with an optional third operator allowed to enter to perform procedure reading and place-keeping only. Support outside the tent was provided by radiological controls, maintenance, industrial hygiene, industrial safety, nuclear safety/criticality, and environmental.

The transfer, disassembly, repackaging, and return to storage activities associated with disassembly of SNL experimental assemblies posed a variety of physical and chemical hazards. These include: material handling, pinching/crushing, radiation, cut hazards, fire, slips and trips, ergonomics, electrical, pressurized systems, heavy metals, asbestos, sodium, uranium, and asphyxiants. Controls for each of these hazards were developed to protect workers both inside and outside the containment tent.

Mock-ups of all dismantling equipment and readiness assessments, including surrogate work evolutions, were conducted to test the preparedness of people, paper in the form of operating procedures, and places, where assemblies would be stored or processed. Valuable worker experience was gained as a result of these efforts and a variety of modifications were made to procedures and equipment to improve the odds for mission success. Once all assessment 
findings had been closed to the satisfaction of the assessment team, actual dismantlement operations commenced. To date, seven of the experimental assemblies have been processed with relatively few surprises.

Many lessons were learned throughout the planning and execution of the dismantling activities. The most cited lesson learned relates to the use of realistic mock-ups to test workers and equipment. The mock-ups utilized full-scale surrogate assemblies complete with internal nested shell and instrument layers and an embedded PCV. This realism allowed the disassembly staff to gain proficiency in tool use and handling methods to successfully remove the outer layers. Modifications to equipment and procedures were made to enhance the workers' opportunity for success and reduce exposure times. Another important lesson learned is that processing order can have a significant impact on task efficiency and exposure to hazards. By processing similar experimental assemblies consecutively and ordering by complexity and radiation level, workers gained the ability to carry experience from one disassembly operation to the subsequent assembly. This reduces the time required to perform subsequent tasks, reducing overall worker exposure to radiation. Potential exposure to asbestos was also reduced as a result of processing order since all the asbestos-containing assemblies are processed last.

The combination of involving all impacted disciplines early in the planning process, identifying applicable requirements, coordinating staff functions, mocking up all dismantlement tasks, and performing self-assessments prior to beginning operations are considered crucial elements contributing to the success the dismantling phase thus far. This is supported by the relatively issue-free performance by the project staff during the first two-thirds of radioactive experimental assembly processing. It is of note that many of the lessons learned within this phase 
of the project can be applied not only to the next phase of the project, but also to virtually any other project. 


\section{References Cited}

Agency for Toxic Substances and Disease Registry (2009). Environmental Health and Medicine Information; Uranium Toxicity - What are the Physiological Effects of Uranium Exposure?; May; http://www.atsdr.cdc.gov/csem/csem.asp?csem=16\&po=11.

Bunker, Merle E. (1983). Los Alamos Science; Winter/Spring 1983; pg. 128; http://library.lanl.gov/cgi-bin/getfile?07-14.pdf.

Chemicool (2012). Interactive Periodic Table; Sodium Element Facts; October; http://www.chemicool.com/elements/sodium.html.

Cochran, Thomas B., Harold A. Feiveson, Frank von Hippel (2008). Fast Breeder Reactor Programs: History and Status; Research Report 8; International Panel on Fissile Materials; Chapter 7; Fast Reactor Development in the United States; 89-94; http://fissilematerials.org/library/rr08.pdf.

Coleman, Aaron (2009). Clinch River and Fast Breeder Reactors; Stanford University; December; http://large.stanford.edu/courses/2009/ph204/coleman2/.

Conceptual Design Report for Sandia Sodium Debris Bed Material Treatment (2011). Idaho National Laboratory; Project No. 29890; INL/MIS-11-22596, Revision 1; November. Contractor Readiness Assessment (2014). Idaho National Laboratory; Contractor Readiness Assessment for Sandia Sodium Debris Bed Canister Disassembly; IAS-141244; March.

Croft, Kevin M. (2013). SNL Sodium Debris Bed Treatment Project; Idaho National Laboratory; April; pg. 2.

Engineering Calculations and Analysis Report (2011). Evaluation of the Radiation Dose Rates on the Sodium Debris Beds; ECAR-1456; May. 
Engineers Edge. Stainless Steel Specification and Composition Table Chart; Chemical Composition Chart for Stainless Steel; http://www.engineersedge.com/stainless steel.htm.

European Nuclear Society. Nuclear Power Plants, World-wide; Photograph of light bulbs powered by Experimental Breeder Reactor - I; Google images; http://www.euronuclear.org/info/encyclopedia/n/nuclear-power-plant-world-wide.htm.

Frost, Brian R. T. (1996). Argonne's Nuclear Science and Technology Legacy; A Brief History of Materials R\&D at Argonne National Laboratory from the Met Lab to Circa 1995; United States Department of Energy; Argonne National Laboratory; http://www.ne.anl.gov/About/legacy/materials/.

Functional and Operational Requirements (2011). Idaho National Laboratory; Treatment System for Sandia National Laboratories Debris Bed Material; TFR-760; March.

Government Printing Office, (2012). Code of Federal Regulation; Title 40 - Protection of Environment; Part 261 - Identification and Listing of Hazardous Waste; July; http://www.gpo.gov/fdsys/pkg/CFR-2012-title40-vol27/xml/CFR-2012-title40-vol27part261.xml.

Laboratory-Wide Procedure (2006). Idaho National Laboratory; Large Area Containments; LWP-15003; Revision 0; December.

Mactech Europe Limited. Cold Pipe Cutting and Bevelling Machines; Clamshell Lathes; Google images; http://mactecheurope.co.uk/machines/cold-pipe-cutting-bevelling-machines/.

Management Self-Assessment (2013). Idaho National Laboratory; Final Report: Management Self-Assessment (MSA) for Sandia Sodium Debris Bed Canister Disassembly; IAS14803; October. 
Mock-up Test Plan (2012); Idaho National Laboratory; Sandia Sodium Debris Bed Recovery and Disposition Mock-up Test Plan; PLN-4164; May.

Molybdenum.com. Molybdenum Material Safety Data Sheet; Section V - Health Hazard Information; http://molybdenum.com/health.pdf.

Niko Steel Industries. Other Non-Ferrous Metals; Chemical Composition of Monel, Hastelloy, Incoly, and Inconel; http://www.nikosteel.com/ferous_metal.htm.

Nuclear Material Control and Accountability (2005). United States Department of Energy; Office of Security and Safety Performance Assurance; DOE Manual 470.4-6; August.

Occupational Safety and Health Administration (1996). United States Department of Labor; 29 CFR 1926.1101; Subpart Z; Toxic and Hazardous Substances; 61 Federal Register 31432; http://www.gpo.gov/fdsys/pkg/CFR-2011-title29-vol8/pdf/CFR-2011-title29vol8-sec1926-1101.pdf.

Panoramio.com. Experimental Breeder Reactor - I; Google images; http://www.panoramio.com/photo/25828210.

Project Execution Plan (2012). Idaho National Laboratory; SNL Sodium Debris Bed Material Treatment, Project No. 29890; PLN-4133; Revision 0; September.

Ragheb, M. (2010). Debris Bed Cooling; pg. 1; http://mragheb.com/NPRE\%20457\%20CSE\%20462\%20Safety\%20Analysis\%20of\%20N uclear\%20Reactor\%20Systems/Debris\%20Beds\%20Cooling.pdf.

Ragheb, M. (2010). Experimental Breeder Reactor Number 1, EBR-I Criticality Accident; pg. 2; http://mragheb.com/NPRE $\% 20457 \% 20 \mathrm{CSE} \% 20462 \% 20$ Safety $\% 20$ Analysis $\% 20$ of $\% 20 \mathrm{~N}$ uclear\%20Reactor\%20Systems/Experimental\%20Breeder\%20Reactor\%20Number\%201 \%20\%20EBRI\%20Criticality\%20Accident.pdf. 
Science Lab, Chromium, (2013). Material Safety Data Sheet; Section 11 - Toxicological Information; May; http://www.sciencelab.com/msds.php?msdsId=9927136.

Science Lab, Nickel, (2013). Material Safety Data Sheet; Section 11 - Toxicological Information; May; http://www.sciencelab.com/msds.php?msdsId=9927372.

Technical Safety Requirements Procedure (2015). Idaho National Laboratory; Laboratory Instruction; Sandia Sodium Debris Bed Experiments Dismantlement System; ZPPR-OI019; Revision 7; January.

The Future of Things (2006). Americium Power Source; October 2006; http://thefutureofthings.com/3015-americium-power-source/

Trinh, Tri Q., Chris R. Barth (2006). Sodium Debris Bed Experiment Data Package; Sandia National Laboratory; SAND2006-5317P; August.

United States Department of Energy (2012). Natural Phenomena Hazards Analysis and Design Criteria for DOE Facilities; DOE-STD-1020-2012; December.

United States Environmental Protection Agency (2015). Asbestos: Learn About Asbestos; February; http://www2.epa.gov/asbestos/learn-about-asbestos\#asbestos. von Hippel, Frank (2008). Fast Breeder Reactor Programs: History and Status; Research Report 8; International Panel on Fissile Materials; Chapter 1; Overview: The Rise and Fall of Plutonium Breeder Reactors; 2-10; http://fissilematerials.org/library/rr08.pdf. 